\title{
A ATUAÇÃO DO PODER JUDICIÁRIO BRASILEIRO NOS BIOMAS AMAZÔNIA E CERRADO VISANDO COMBATER O AQUECIMENTO GLOBAL
}

\author{
ACTIVITY OF THE BRAZILIAN JUDICIARY IN THE AMAZON AND \\ CERRADO BIOMES AIMED AT COMBATING GLOBAL WARMING
}

\author{
Diogo Andreola Serraglio* \\ Heline Sivini Ferreira** \\ Rullyan Levi Maganhati Mendes ${ }^{* * *}$
}

\begin{abstract}
Resumo: Considerando a entrada em vigor da Política Nacional sobre Mudança do Clima no ano de 2009, pretende-se analisar como o Poder Judiciário brasileiro tem se posicionado, desde então, diante das inexpressivas metas adotadas pelo Brasil com o intuito de reduzir as suas emissões de gases de efeito estufa na atmosfera, salvaguardando, por conseguinte, o equilíbrio ambiental dos biomas Amazônia e Cerrado. Seguindo o método de procedimento dedutivo, ambiciona-se atingir os seguintes objetivos específicos: inicialmente, examinar os principais aspectos de ambos os biomas, salientando não apenas suas particularidades, mas também os impactos ambientais que intensificam os efeitos do aquecimento global; posteriormente, tratar da Política Nacional sobre Mudança do Clima, com especial enfoque nos resultados até então alcançados pelo Plano de Ação para a Prevenção e Controle de Desmatamento na Amazônia Legal (PPCDAm) e pelo Plano de Ação para Prevenção e Controle do Desmatamento e das Queimadas no Cerrado (PPCerrado); e, por fim, uma vez demonstrado que as metas estabelecidas independem de esforços genuínos por parte do Brasil, verificar a apreciação judicial do tema. Almeja-se, portanto, evidenciar a sensibilidade do Poder Judiciário brasileiro à causa ambiental, intervindo com vistas à manutenção do equilíbrio ecológico face às mudanças climáticas.
\end{abstract}

Palavras-chave: Mudanças climáticas; Floresta Amazônica; Cerrado; Política Nacional sobre Mudança do Clima; Poder Judiciário.

\footnotetext{
* Doutorando em Direito pela Pontifícia Universidade Católica do Paraná (PUCPR). Bolsista da Coordenação de Aperfeiçoamento de Pessoal de Nível Superior (CAPES). Mestre em Direito pela PUCPR. Membro da Comissão Mundial de Direito Ambiental da International Union for Conservation of Nature (IUCN) e da Rede Sul Americana para as Migrações Ambientais (RESAMA). Advogado. Curitiba, Paraná, Brasil. Contato: diogo.aserraglio@gmail.com

** Doutora em Direito pela Universidade Federal de Santa Catarina (UFSC. Mestre em Direito pela UFSC. Professora Adjunta do Curso de Graduação e do Programa de Pós-Graduação em Direito da Pontifícia Universidade Católica do Paraná (PUCPR). Professora Colaboradora do Curso de PósGraduação da UFSC. Pesquisadora do Grupo de Pesquisa Direito Ambiental e Ecologia Política na Sociedade de Risco (UFSC), do Grupo de Pesquisa Meio Ambiente: Sociedades Tradicionais e Sociedade Hegemônica (PUCPR). Coordenadora Regional da Associação dos Professores de Direito Ambiental do Brasil (APRODAB). Membro da Commission on Environmental Law (International Union for Conservation of Nature). Curitiba, Paraná, Brasil. Contato: hsivini@ yahoo.com.br

*** Mestrando em Direito pela Pontifícia Universidade Católica do Paraná (PUCPR). Bolsista da Coordenação de Aperfeiçoamento de Pessoal de Nível Superior (CAPES). Advogado. Curitiba, Paraná, Brasil. Contato: rullyan@ hotmail.com.
} 
Abstract: With the National Policy on Climate Change taking effect in 2009, this article aims to assess how the Brazilian Judiciary has positioned itself since that time, when faced with the unimpressive goals adopted by Brazil to reduce its greenhouse gas emissions into the atmosphere and safeguarding the environmental balance of the Amazon and Cerrado biomes as a result. The deductive approach methodology was followed with the intention of achieving the following specific objectives: first, to examine the main aspects of both biomes, highlighting not only their peculiarities, but also the environmental impact, intensifying the effects of global warming; thereafter, to address the National Policy on Climate Change, with special focus on the results obtained thus far by the Action Plan for Deforestation Prevention and Control in the Legal Amazon (PPCDAm) and the Action Plan for Deforestation and Fire Prevention and Control in the Cerrado (PPCerrado); and, finally, having demonstrated that the goals adopted are not based on genuine efforts by Brazil, to evaluate the judicial handling of the subject. It thus aims to demonstrate the sensitivity of the Brazilian Judiciary to the environmental cause when faced with climate change in intervening with a view to maintaining the ecological balance.

Keywords: Climate change; Amazon rainforest; Cerrado; National Policy on Climate Change; Judiciary.

\section{INTRODUÇÃO}

O presente estudo volta-se à análise de como o Poder Judiciário brasileiro tem se posicionado diante das metas pouco expressivas adotadas pelo Brasil com o propósito de reduzir as suas emissões de gases de efeito estufa (GEE) na atmosfera, resguardando, como consequência, o dinâmico equilíbrio ecológico de dois biomas nacionais, a Amazônia e o Cerrado.

Em face de um constante e desmedido processo de exploração, parte-se, inicialmente, da contextualização de ambos os biomas, procurando-se demonstrar, de um lado, as singularidades de suas riquezas e, de outro, os impactos ambientais que, decorrentes do uso insustentável do solo, potencializam os efeitos negativos do aquecimento global e colocam o Brasil na incômoda posição de quinto maior emissor de GEE do planeta.

Diante disso, a pesquisa direciona-se à Política Nacional sobre Mudança do Clima (Lei n. 12.187/2009), que, além de ratificar o compromisso internacional voluntário de reduzir entre $36,1 \%$ e 38,9\% as emissões brasileiras de GEE projetadas até 2020, estabelece planos setoriais de mitigação e de adaptação às mudanças climáticas e planos de ação para a prevenção e controle do desmatamento nos biomas. 
A atuação do poder judiciário brasileiro nos biomas amazônia e cerrado visando combater o aquecimento global

A investigação dos resultados obtidos pelo Plano de Ação para a Prevenção e Controle de Desmatamento na Amazônia Legal (PPCDAm) e pelo Plano de Ação para Prevenção e Controle do Desmatamento e das Queimadas no Cerrado (PPCerrado), entretanto, evidenciarão que se está diante de uma legislação cuja dimensão simbólica expressa-se por meio da adoção de um compromisso que, apesar de politicamente relevante, não representa propriamente um desafio para o país.

Assim sendo, diante de metas cujo alcance independe de esforços genuínos

por parte do Brasil, verificar-se-á que as práticas de uso insustentável do solo acabam sendo judicializadas, fazendo com que o combate aos efeitos nocivos do aquecimento global passe também a ser objeto de apreciação judicial.

Em suma, pretende-se explanar que, embora as metas de redução de GEE estabelecidas para os biomas Amazônia e Cerrado sejam deficientes, o Poder Judiciário brasileiro tem se mostrado sensível à causa ecológica, atuando no sentido de assegurar as condições mínimas para a preservação dos seus atributos ecológicos face às mudanças climáticas.

\section{A DIMENSÃO DAS MUDANÇAS CLIMÁTICAS NOS BIOMAS AMAZÔNIA E CERRADO}

Cumpre observar, preliminarmente, que o aumento da temperatura média do planeta é um dos problemas ambientais mais questionados deste século. Esse fenômeno foi acelerado em razão da emissão desenfreada de GEE na atmosfera pelas ações antropogênicas em busca do crescimento econômico (BRADBROOK; OTTINGER, 2003, p. 13-14). Nessa perspectiva, Leal-Arcas (2013, p. 28) destaca que o aquecimento da superfície terrestre mostra-se como uma ameaça não apenas para a humanidade, mas também para a sustentabilidade do ambiente. Trata-se, pois, de uma questão global, a qual trará impactos substanciais aos sistemas social, econômico e ambiental.

O Quinto Relatório de Avaliação (AR-5) do Painel Intergovernamental sobre Mudanças Climáticas (IPCC, 2013, p. 18), publicado em 2014, acentua que as atividades humanas alteraram e continuam a alterar a composição atmosférica da superfície da Terra. É, portanto, incontroverso que houve uma elevação da temperatura média global no período compreendido entre os anos de 1951 e 2010. Nesse cenário, a emissão de GEE desponta como a principal causa do aquecimento da superfície terrestre, cuja temperatura aumentou, nesse intervalo de tempo, entre 0.5 e $1.3{ }^{\circ} \mathrm{C}$ (grau 
Celsius). Ademais, a média anual do aquecimento terrestre constatada a partir do século XX propiciou a inversão da tendência de resfriamento em longo prazo dos últimos 5.000 anos nas altas latitudes do hemisfério norte. Isto é, no tocante às temperaturas médias anuais desse hemisfério, o período compreendido entre os anos de 1983 a 2012 foi, muito provavelmente, o que teve os 30 anos mais quentes dos últimos 1.400 anos (IPCC, 2013, p. 25-26).

Para que a temperatura média do globo não ultrapasse $2{ }^{\circ} \mathrm{C}$ em relação aos índices constatados no início do processo de industrialização, a concentração de dióxido de carbono $\left(\mathrm{CO}_{2}\right)$ na atmosfera não poderá exceder 550 partes por milhão em volume (ppmv) (JURAS, 2008, p. 15). Nesse sentido, o AR-5 apontou que o aumento da concentração de $\mathrm{CO}_{2}$ na atmosfera subiu de 278 ppmv, em 1750, para 390.5 ppmv, em 2011, tendo a quantidade desse composto químico aumentado 4.0 pentagramas de carbono por ano (PgC/ano) ${ }^{1}$ na primeira década do século XXI (IPCC, 2013, p. 5).

Por isso, deve-se considerar que a sobrecarga ocasionada pelo constante aumento da poluição atmosférica tem acarretado efeitos negativos sobre o ambiente, especialmente na América do Sul, uma região que abriga ecossistemas singulares, com padrões climáticos definidos. De fato, o continente sul-americano vem sofrendo diversos impactos ambientais, os quais resultam, sobretudo, da mudança do uso do solo e da intensificação da variabilidade climática regional (IPCC, 2014, p. 1504).

As implicações das mudanças climáticas mostram-se cada vez mais perceptíveis na América do Sul: assinala-se, no período compreendido entre os anos de 2000 e 2013, a incidência de aproximadamente 610 eventos climáticos extremos, culminando na morte de 13.883 pessoas, afetando, direta e indiretamente, cerca de 53,8 milhões de indivíduos e causando uma perda econômica no importe de US\$ 52,3 bilhões (IPCC, 2014, p. 1504). Ademais, perturbações futuras ainda incluem a extinção significativa de espécies, sobretudo nas regiões tropicais; a substituição de remanescentes florestais tropicais por savanas, assim como da vegetação semiárida por árida; o aumento do número de pessoas que vivem sob o risco real de escassez de água; a maior incidência de pragas e doenças relacionadas às atividades agrícolas; bem como a desestruturação de regiões costeiras em razão da elevação do nível do mar e de eventos climáticos extremos (IPCC, 2014, p. 1504).

De acordo com o AR-5, as mudanças no uso da terra, além de contribuírem significativamente para a degradação ambiental, aceleram os efeitos do aquecimento R. Fac. Dir. UFG, v. 42, n. 2, p.11-47, maio/ago. 2018 
A atuação do poder judiciário brasileiro nos biomas amazônia e cerrado visando combater o aquecimento global

global. Observa-se que o desflorestamento e a consequente degradação do solo decorrem, sobretudo, da expansão agrícola, estando essa também relacionada ao aumento da precipitação regional, que acaba por afetar os entornos da Floresta Amazônica e do Cerrado (IPCC, 2014, p. 1502).

É nesse contexto que o exame dos principais aspectos dos biomas Amazônia e Cerrado torna-se necessário. A seguir, serão expostos não apenas suas particularidades, mas também os impactos ambientais que contribuem para a intensificação das consequências do aquecimento global.

\subsection{O DESMATAMENTO DA FLORESTA AMAZÔNICA E AS MUDANÇAS CLIMÁTICAS}

A Floresta Amazônica resguarda a área de influência da bacia hidrográfica do Rio Amazonas e contém a maior extensão de vegetação tropical e contínua do planeta Terra, com uma superfície aproximada de 7,8 milhões de quilômetros quadrados $\left(\mathrm{km}^{2}\right)$ distribuída entre nove países: Brasil, Bolívia, Colômbia, Equador, Guiana, Guiana Francesa - território ultramarino da França -, Peru, Suriname e Venezuela (SANTOS, 2013, p. 11).

Tenha-se presente que cerca de $80 \%$ desse macroecossistema ainda se encontra preservado. Considerada o grande berço da diversidade biológica planetária, a região amazônica abriga cerca de 1/3 de todas as espécies terrestres conhecidas (IPAM, 2011, p. 25). Nela, encontram-se catalogadas uma variedade de 40.000 plantas superiores, 425 gêneros de mamíferos, 1.300 categorias de aves diversas, 371 espécies de répteis, 427 tipos de anfíbios, assim como cerca de 3.500 espécies de peixes de água doce (CADERNOS ADENAUER X, 2010, p. 35).

Nesse contexto, é de ser relevado que o Brasil possui $68 \%$ de toda a Floresta Amazônica em seu território, o que representa de $10 \%$ a $20 \%$ de toda a variabilidade genética terrestre conhecida e o refúgio de $40 \%$ a $70 \%$ das espécies animais e vegetais em regiões tropicais (MAZZUOLI; GALVÃO, 2011, p. 1). Em vista disso, torna-se compreensível que o $\S 4^{\circ}$ do artigo 225 da Constituição da República Federativa do Brasil de 1988 tenha reconhecido a Floresta Amazônica brasileira como patrimônio nacional e, ao assim fazê-lo, determina que a sua utilização deve ocorrer dentro de condições que assegurem a preservação do ambiente, inclusive quanto ao uso dos recursos naturais. 
Assim sendo, cumpre observar, mesmo que sucintamente, a distinção entre o que se chama bioma amazônico brasileiro e a denominada Amazônia Legal. Enquanto o primeiro termo é utilizado para caracterizar um grande sistema ecológico localizado em território nacional, ou seja, para definir um conjunto de ecorregiões, fauna, flora, dinâmicas e processos ecológicos similares que ocorrem na região norte do Brasil, perfazendo uma superfície aproximada de 4,1 milhões de $\mathrm{km}^{2}$; o segundo inclui, além de toda a porção da bacia hidrográfica amazônica situada em terras brasileiras, áreas de campos naturais situadas nos arredores, totalizando pouco mais de 5 milhões de $\mathrm{km}^{2}$ (MAZZUOLI; GALVÃO, 2011, p. 1). Isto é, além do bioma amazônico, a Amazônia Legal engloba $37 \%$ do bioma Cerrado e aproximadamente $40 \%$ do bioma Pantanal ${ }^{2}$. Criada pela Lei n. 1.806/1953, a Amazônia Legal surge como um conceito político que se propõe a viabilizar um melhor planejamento socioeconômico de áreas específicas e com significativas semelhanças (AMARAL; VALE, 2010, p. 4). Compreendendo nove estados brasileiros ${ }^{3}$ pertencentes à bacia hidrográfica amazônica e suas respectivas localidades subjacentes, a Amazônia Legal equivale a 59\% de todo o território nacional.

Uma vez constatada a riqueza e a diversidade que encontram abrigo na Floresta Amazônica, cumpre destacar a sua relevância para o equilíbrio climático regional e global (IPAM, 2011, p. 25). Isso porque as florestas tropicais promovem a autorregulação da temperatura terrestre ao absorver $\mathrm{CO}_{2}$ e devolver oxigênio $\left(\mathrm{O}_{2}\right)$ à atmosfera por meio da fotossíntese, desempenhando um importante papel na fixação do $\mathrm{CO}_{2}$, um dos principais GEE responsáveis pelo aquecimento global (MAZZUOLI; GALVÃO, 2011, p. 2). Dessa maneira, tem-se que a diversidade biológica da bacia hidrográfica amazônica é imprescindível para a manutenção dos seus processos ecológicos, a exemplo do ciclo do carbono (C) (CAPOBIANCO, 2001, p. 178-179).

Entretanto, a degradação de remanescentes florestais tropicais, como o bioma amazônico, ameaça esse equilíbrio ao emitir toneladas de $\mathrm{CO}_{2}$ que ficam armazenadas não apenas no solo, mas também na vegetação. Vale lembrar que, na condição de reservatórios ${ }^{4}$, os remanescentes florestais possibilitam o estoque de $\mathrm{CO}_{2}$ na forma orgânica; como sumidouros, são capazes de remover o $\mathrm{CO}_{2}$ da atmosfera por meio do processo físico-químico denominado fotossíntese; e, sob a denominação de fontes, liberam carbono na atmosfera por meio da respiração (BORGES, 2011, p. 57).

Apesar de se reconhecer que as florestas são imprescindíveis para a mitigação das adversidades climáticas e para os processos de adaptação dos R. Fac. Dir. UFG, v. 42, n. 2, p.11-47, maio/ago. 2018 
A atuação do poder judiciário brasileiro nos biomas amazônia e cerrado visando combater o aquecimento global

ecossistemas aos efeitos do aquecimento global, atividades como o desflorestamento e as queimadas, além de prejudicarem o ciclo do carbono como processo ecológico essencial, provocam também uma maior liberação desse elemento químico no ambiente e, por consequência, a intensificação do aquecimento da superfície terrestre (CAPOBIANCO, 2001, p. 178-179).

Nesse contexto, as causas da degradação florestal se encontram diretamente relacionadas à conversão de matas em áreas destinadas à agricultura por meio das queimadas, à criação de gado, à extração de madeira e aos incêndios florestais decorrentes da intensificação dos períodos de estiagem na região. Importante destacar que grande parte desse desmatamento é promovida por subsídios destinados ao agronegócio e à pecuária, assim como por políticas públicas que priorizam o investimento em infraestrutura (IPAM, 2011, p. 29).

De acordo com o Instituto do Homem e Meio Ambiente da Amazônia (IMAZON, 2015, p. 6), um volume total de 48,6 bilhões de toneladas de dióxido de carbono equivalente ${ }^{5}$ ( $\mathrm{CCO}_{2} \mathrm{eq}$ ) foi emitido pelo Brasil entre os anos de 1990 e 2013. Ressalta-se que aproximadamente $62 \%$ desse valor decorrem do setor de mudanças do uso da terra, seguido de $17 \%$ pelo setor agropecuário e, por fim, $15 \%$ do setor energético. Logo, tendo em vista que uma das principais fontes de emissão do setor de mudanças de uso da terra é o desflorestamento, tem-se, no respectivo período, a emissão aproximada 30,197 bilhões de $\mathrm{tCO}_{2} \mathrm{eq}$, oriundas, sobretudo, do desmatamento e da degradação ambiental da Amazônia Legal.

Frisa-se que, até o ano de 2004, o acelerado processo de derrubada de remanescentes florestais na Amazônia Legal ensejou índices de desmatamento superiores a $15.000 \mathrm{~km}^{2}$ por ano. Em termos de volume de emissão, isso significou o lançamento de cerca de 22 bilhões de $\mathrm{tCO}_{2}$ eq na atmosfera no período compreendido entre os anos de 1990 e 2004, ou seja, uma média de 1,5 bilhão de $\mathrm{tCO}_{2}$ eq por ano. A partir de 2004, com a implementação de diversas ações objetivando a contenção do desmatamento de remanescentes florestais na Amazônia Legal, constatou-se uma redução da média anual de emissões de GEE na atmosfera. No período compreendido entre os anos de 2005 e 2013, portanto, foi emitido um total de 7,8 bilhões de $\mathrm{tCO}_{2} \mathrm{eq}$, o que significa um volume médio anual de 865 milhões de $\mathrm{tCO}_{2} \mathrm{eq}(\mathrm{IMAZON}, 2015$, p. $6)$. 
Pelo exposto, o uso insustentável do solo, com frequentes desmatamentos e impactos ambientais significativos, coloca o Brasil na incômoda posição de quinto maior emissor de GEE do planeta. A destruição do bioma amazônico brasileiro ainda representa mais da metade do total de GEE emitido pelo país, ou seja, corresponde a $55 \%$ de todas as emissões de GEE no Brasil, contribuindo, assim, para o aceleramento das mudanças climáticas decorrentes do aquecimento global (AMARAL; VALE, 2010, p. 2).

\subsection{O DESMATAMENTO DO CERRADO E AS MUDANÇAS CLIMÁTICAS}

O bioma Cerrado, por sua vez, designa-se pelo contexto geográfico que ocupa pouco menos de um quarto do território brasileiro, em uma área aproximada de 2 milhões de $\mathrm{km}^{2}$ distribuída entre o Distrito Federal e os estados de Goiás, Mato Grosso, Mato Grosso do Sul, Tocantins, Maranhão, Bahia, Piauí, Minas Gerais, São Paulo e Paraná.

Trata-se, pois, da savana tropical mais rica em biodiversidade do país, englobando aproximadamente 10 mil espécies de plantas, sendo 4 mil dessas endêmicas ${ }^{6} ; 837$ categorias de aves diversas e 161 gêneros de mamíferos, sendo 45 desses endêmicos (PÁDUA, 2009, p. 134). Em virtude de sua extensão, é composto por vários tipos de vegetação: campestre, arbustiva, herbácea, savânica e florestal; “[...] compartilhando áreas de transição e mantendo fluxos gênicos com outros biomas existentes no Brasil" (ALVARENGA, 2013, p. 31), de modo que “[...] nenhum outro bioma sul-americano possui zonas de contatos biogeográficos tão distintos, conferindolhe um aspecto ecológico único" (MMA, 2014, p. 28).

Ao contrário da Floresta Amazônica, o Cerrado brasileiro não dispõe do status constitucional de patrimônio nacional, o que, em termos práticos, significa menor atenção do Poder Público e menos recursos para sua manutenção e uso sustentável, como se fosse um bioma com menor importância, com menor valor econômico se comparado a outras regiões florestais e, portanto, com uma visibilidade arrefecida $^{7}$ (ALVARENGA, 2013, p. 010).

Nesse lanço, somam 25 anos sem tramitação no Congresso Nacional as tentativas de reconhecimento do Cerrado como patrimônio brasileiro, intento iniciado pela Proposta de Emenda à Constituição (PEC) n. 141, em 1992, restrita ao bioma, e reiniciado pela PEC n. 115, de 1995, atualmente apensada à PEC n. 504, de 2010, que, R. Fac. Dir. UFG, v. 42, n. 2, p.11-47, maio/ago. 2018 
A atuação do poder judiciário brasileiro nos biomas amazônia e cerrado visando combater o aquecimento global

na proposta de reformular o território brasileiro como uma rede de biomas, reuniu, ao lado do Cerrado, também a Caatinga ${ }^{8}$ (PÁDUA, 2009, p. 148).

A resistência política mantida ao longo dos anos em relação à PEC que visa o reconhecimento do Cerrado como patrimônio nacional decorre do receio de que sua aprovação impacte negativamente o avanço do agronegócio no Brasil central. Isso porque, em sendo o Cerrado relevante não apenas em razão de sua contribuição para o meio ambiente, mas também para a economia do país, o desenvolvimento sustentável da região acaba sendo um grande desafio brasileiro (MMA, 2014, p. 17).

Nesse aspecto, pouco ocupado e explorado até meados do século XX, o avanço econômico em direção ao Cerrado se deu a partir da construção de Brasília, na década de 1950, e ganhou fôlego a partir da década de 1960, quando, propagado como "celeiro do mundo" (BRAGA; PIRES, 2002, p. 45), foram elaborados projetos desenvolvimentistas e realizadas pesquisas com o intuito de corrigir a acidez do solo local, favorecendo, nessa perspectiva, a expansão agrícola na região (MELLO-THÉRY; THÉRY, 2014, p. 66).

Assim, apontado hoje como o principal responsável pela ascensão da agricultura brasileira no mercado internacional, reconhece-se que a expansão agropecuária transformou a cobertura do solo do Cerrado (MMA, 2014, p. 10), modificando sobremaneira a paisagem da região - onde, a propósito, constatam-se os maiores índices de desmatamento na Amazônia Legal (VEYRET, 2012, p. 67).

Além do bioma amazônico, repisa-se que a Amazônia Legal engloba 37\% do bioma Cerrado. Nesse lanço, inobstante o Cerrado representar o maior centro de produção de bens primários no Brasil, sendo considerado o propulsor da expansão do agronegócio na produção de carne e grãos e um dos principais produtores de commodities agrícolas do mundo ${ }^{9}$, mais da metade de sua área encontra-se radicalmente alterada em razão do processo de erosão, assoreamento, poluição de aquíferos e contaminação por agrotóxicos (PÁDUA, 2009, p. 13).

A agravar esse contexto, o bioma em questão é “[...] percebido pela sociedade brasileira como um tipo de vegetação pobre, uma reserva de terras a ser desbravada" (VEYRET, 2012, p. 67), “[...] uma área sem beleza e importância ecológica, que pode ser destruída sem maiores problemas para o avanço da agropecuária" (PÁDUA, 2009, p. 133-134). Na esteira dessa mentalidade, as queimadas 
são realizadas de modo contínuo com a equivocada intenção de limpeza do solo (RIZZARDO, 2014, p. 597).

Segundo o AR-5 do IPCC, a maior causa de emissões de GEE no Cerrado advém das mudanças do uso do solo, sobretudo do desmatamento para o desenvolvimento de atividades agropecuárias, como o cultivo da soja e a produção de carne bovina (IPCC, 2014, p. 1502, 1514 e 1515). De tal monta é a intervenção humana na região que o IPCC projeta, até o ano de 2050, a depreciação das condições ambientais mínimas para a manutenção de uma espécie vegetal chamada pequi, uma das espécies que caracterizam o bioma (PÁDUA, 2009, p. 13), afetando, também em uma perspectiva econômica, as comunidades mais pobres, aquelas que tradicionalmente se alimentam desse fruto e comercializam produtos artesanais derivados dele, como cosméticos, licor e óleo (IPCC, 2014, p. 1530).

Nesse panorama, os eventos climáticos extremos de seca e chuva tendem a ser cada vez mais frequentes no bioma e a temperatura pode sofrer variações que vão de $5{ }^{\circ} \mathrm{C}$ a mais de $40{ }^{\circ} \mathrm{C}$, em suas latitudes subtropicais e tropicais, respectivamente. Ademais, os modelos climáticos sinalizam a tendência de aquecimento da temperatura média do Cerrado entre 4 a $5{ }^{\circ} \mathrm{C}$ até o final do século XXI (PBMC, 2015, p. 393-395).

Posto isso, torna-se oportuno o delineamento da política climática em curso no Brasil, para que, na sequência, sejam analisados os seus planos de ação incidentes na Amazônia e no Cerrado, as mais extensas ecorregiões do país.

\section{O BRASIL EM FACE DO AQUECIMENTO GLOBAL: A POLÍTICA NACIONAL SOBRE MUDANÇA DO CLIMA (PNMC)}

Ainda que as investigações científicas sobre o fenômeno das alterações climáticas tenham sido iniciadas no final do século XIX, assinala-se que a emergência desta problemática como uma questão política ocorreu tão somente com a elaboração da Convenção-Quadro das Nações Unidas sobre Mudança do Clima (doravante, Convenção-Quadro), disponibilizada para assinatura durante a Conferência das Nações Unidas sobre Meio Ambiente e Desenvolvimento, realizada no Brasil, em 1992 (RIVERA, 1997, p. 1209-1235). A referida Convenção entrou em vigor em 1994, com a ratificação de 192 Estados, e foi considerada o primeiro acordo ambiental climático a englobar uma parte considerável da comunidade internacional. 
A atuação do poder judiciário brasileiro nos biomas amazônia e cerrado visando combater o aquecimento global

Nesse lanço, convém mencionar que durante a $3^{\text {a }}$ Conferência das Partes $(\mathrm{COP}-3)^{10}$, realizada em Quioto, no Japão, as nações integrantes da Convenção-Quadro homologaram o Protocolo de Quioto ${ }^{11}$, suscitando um comprometimento mais rigoroso de todas as partes envolvidas para a contenção das alterações do clima (LEAL-ARCAS, 2013, p. 190). Estabeleceu-se, então, que os países desenvolvidos reduziriam suas emissões totais de GEE em pelo menos 5\% abaixo dos níveis de 1990 no período de compromisso de 2008 a 2012. Já os países em desenvolvimento, comprometeram-se com a implantação voluntária de sistemas de desenvolvimento sustentável (VIÑUALES, 2015, p. 269).

Tanto a Convenção-Quadro quanto o Protocolo de Quioto foram ratificados pelo Brasil e, assim sendo, passaram a incidir em território nacional. Em particular, o Brasil legitimou o que mais tarde foi convencionado como primeiro período de cumprimento do Protocolo de Quioto (entre os anos de 2008 e 2012) ${ }^{12}$. Em face disso, com o propósito de elaborar estudos, formular políticas e desenvolver estratégias para a mitigação e adaptação aos efeitos das mudanças climáticas, no ano de 2009, durante a reunião da $15^{\mathrm{a}}$ Conferência das Partes (COP-15) do regime climático, realizada em Copenhague, o país assumiu o compromisso voluntário de reduzir entre 36,1\% e 38,9\% as suas emissões projetadas até $2020^{13}$.

Internalizando a meta assumida perante a comunidade internacional, o governo brasileiro estabeleceu a Política Nacional sobre Mudança do Clima (PNMC) por intermédio da Lei n. 12.187, de 29 de dezembro de 2009. Este é, portanto, o marco regulatório das ações de mitigação e adaptação que devem ser adotadas pelo Brasil no combate ao aquecimento global (MILARÉ, 2011, p. 269).

Nesse contexto, é oportuno mencionar que as emissões nacionais de GEE para o ano de 2020 estão estimadas em 3.236 milhões de tCO2eq, majoritariamente provenientes de mudanças de uso da terra $(1.404 \text { milhões de tCO2eq })^{14}$. Por essa razão, o artigo $6^{\circ}$ da PNMC elenca diversos instrumentos com vistas à redução da emissão de GEE, destacando-se o Plano Nacional sobre Mudança do Clima, em vigor desde 2008.

Com a posterior regulamentação da PNMC por meio do Decreto Legislativo n. 7.390, de 9 de dezembro de 2010, definiu-se que o Plano Nacional sobre Mudança do Clima seria integrado por planos de ação para a prevenção e controle do desmatamento dos biomas e por planos setoriais de mitigação e de adaptação às mudanças climáticas. 
Em conjunto, esses planos almejam a consolidação de uma economia de baixo consumo de carbono em setores estratégicos da economia (BORGES, 2011, p. 48).

De acordo com o artigo $3^{\circ}$ do Decreto n. 7.390/2010, os seguintes planos setoriais devem ser inicialmente considerados: o Plano Decenal de Expansão de Energia, vinculado ao objetivo de expandir a oferta hidroelétrica, de biocombustíveis, de fontes alternativas renováveis, notadamente centrais eólicas, pequenas centrais hidroelétricas e bioeletricidade, além de incrementar a eficiência energética ${ }^{15}$; o Plano para a Consolidação de uma Economia de Baixa Emissão de Carbono na Agricultura, que deve contemplar a recuperação de pastagens degradadas, a ampliação do sistema de integração lavoura-pecuária-floresta, a expansão da prática de plantio direto na palha, a expansão da fixação biológica de nitrogênio em áreas de cultivo em substituição ao uso de fertilizantes nitrogenados, a expansão do plantio de florestas e a ampliação do uso de tecnologias para tratamento de dejetos de animais ${ }^{16}$; e o Plano de Redução de Emissões da Siderurgia, que deve objetivar o incremento da utilização na siderurgia do carvão vegetal originário de florestas plantadas e a melhoria na eficiência do processo de carbonização $^{17}$.

Os planos de ação, também de acordo com o que determina o artigo $3^{\circ}$ do Decreto n. 7.390/2010, subdividem-se em: Plano de Ação para a Prevenção e Controle do Desmatamento na Amazônia Legal (PPCDAm) e Plano de Ação para a Prevenção e Controle do Desmatamento e das Queimadas no Cerrado (PPCerrado), os quais serão analisados a seguir.

\subsection{O PLANO DE AÇÃO PARA A PREVENÇÃO E CONTROLE DO DESMATAMENTO NA AMAZÔNIA LEGAL (PPCDAm)}

O Plano de Ação para a Prevenção e Controle do Desmatamento na Amazônia Legal (PPCDAm) antecede em muito a publicação do Decreto Legislativo n. 7.390/2010. Lançado oficialmente no ano de 2004 em virtude de um aumento de 40\% no índice de desmatamento anual da Amazônia Legal (FUNDO AMAZÔNIA, 2013), constitui-se na política pública de controle do desmatamento com maior tempo de vigência no território brasileiro. Com períodos definidos de implementação, o PPCDAm encontra-se atualmente em sua quarta fase de execução $(2016-2020)^{18}$.

Cooptado em 2009 pela PNMC, e com ela agora alinhado, o PPCDAm tem como objetivo primordial a redução de $80 \%$ dos índices anuais de desmatamento na R. Fac. Dir. UFG, v. 42, n. 2, p.11-47, maio/ago. 2018 
A atuação do poder judiciário brasileiro nos biomas amazônia e cerrado visando combater o aquecimento global

Amazônia Legal em relação à média verificada entre os anos de 1996 a $2005^{19}$. De acordo com o Anexo do Decreto Legislativo n. 7.390/2010, a taxa de desmatamento projetada para o ano de 2020 na Amazônia Legal equivale à taxa média de desmatamento aferida no bioma pelo Projeto de Monitoramento do Desflorestamento na Amazônia Legal (PRODES) do Instituto Nacional de Pesquisas Espaciais (INPE, 2017) entre os anos de 1996 e 2005, o que pode visualizado no quadro a seguir.

Quadro 1 - Taxa média de desmatamento na Amazônia Legal $\left(\mathrm{km}^{2}\right)$

\begin{tabular}{|c|c|c|c|c|c|c|c|c|c|c|}
\hline 1996 & $\mathbf{1 9 9 7}$ & $\mathbf{1 9 9 8}$ & $\mathbf{1 9 9 9}$ & $\mathbf{2 0 0 0}$ & $\mathbf{2 0 0 1}$ & $\mathbf{2 0 0 2}$ & $\mathbf{2 0 0 3}$ & $\mathbf{2 0 0 4}$ & $\mathbf{2 0 0 5}$ & $\mathbf{2 0 2 0}$ \\
\hline 18.161 & 13.227 & 17.383 & 17.259 & 18.226 & 18.165 & 21.651 & 25.396 & 27.772 & 19.014 & 19.625 \\
\hline
\end{tabular}

Fonte: PRODES

Cumpre mencionar que o Anexo do Decreto Legislativo n. 7.390/2010 aponta como sendo de $19.535 \mathrm{~km}^{2}$ a média do desmatamento da Amazônia Legal entre os anos de 1996 e 2005. Investigou-se, todavia, que à época da entrada em vigor do referido documento, as taxas de desmatamento divulgadas pelo PRODES referentes ao período compreendido entre 2002 e 2005 ainda eram estimadas, o que justifica a modesta diferença (INPE, 2017). Com os números consolidados, reconheceu-se então como objetivo do PPCDAm a redução do índice de desmatamento na Amazônia Legal em $15.700 \mathrm{~km}^{2}$ a cada ano.

Intencionando uma melhor ilustração da meta acima referida, em uma contagem a contrario sensu, isso significa que, a partir da entrada em vigor da PNMC, apenas $3.925 \mathrm{~km}^{2}$ podem ser desmatados anualmente na Amazônia Legal, contribuindo, por conseguinte, para a redução entre $36,1 \%$ e $38,9 \%$ das emissões brasileiras de GEE projetadas até 2020. Dito isso, interessam os dados do PRODES (INPE, 2017) a respeito dos índices de desmatamento na Amazônia Legal entre os anos de 2009 e $2016^{20}$, assim como o percentual de redução em relação à média (1996-2005) que esses valores representam, conforme se verifica na sequência. 
Quadro 2 - Desmatamento na Amazônia Legal

\begin{tabular}{|c|c|c|}
\hline ANO & TAXA DE DESMATAMENTO & $\begin{array}{c}\text { PERCENTUAL DE } \\
\text { REDÇÃO EM RELAÇÃO } \\
\text { MÉ ÁA (1996-2005) }\end{array}$ \\
\hline $\mathbf{2 0 0 9}$ & $7.464 \mathrm{~km}^{2}$ & $62 \%$ \\
\hline $\mathbf{2 0 1 0}$ & $7.000 \mathrm{~km}^{2}$ & $64 \%$ \\
\hline $\mathbf{2 0 1 1}$ & $6.418 \mathrm{~km}^{2}$ & $67 \%$ \\
\hline $\mathbf{2 0 1 2}$ & $4.571 \mathrm{~km}^{2}$ & $77 \%$ \\
\hline $\mathbf{2 0 1 3}$ & $5.891 \mathrm{~km}^{2}$ & $70 \%$ \\
\hline $\mathbf{2 0 1 4}$ & $5.012 \mathrm{~km}^{2}$ & $74 \%$ \\
\hline $\mathbf{2 0 1 5}$ & $6.207 \mathrm{~km}^{2}$ & $68 \%$ \\
\hline $\mathbf{2 0 1 6}$ & $7.983 \mathrm{~km}^{2}$ & $59 \%$ \\
\hline
\end{tabular}

Fonte: PRODES (taxa de desmatamento) e autores (percentual)

Sendo de $80 \%$ a meta estabelecida, percebe-se que houve uma significativa redução dos índices anuais de desmatamento na Amazônia Legal particularmente entre os anos de 2011 e 2015.

Em 2012, em especial, quando a redução foi de $77 \%$ em relação à média registrada entre os anos de 1996 a 2005, verifica-se que o compromisso anual foi praticamente alcançado. Em razão desse feito, afirma-se que 2012 reflete a ruptura de dois mitos nacionais, “[...] o da impotência com relação à capacidade da sociedade brasileira de controlar o desmatamento na Amazônia e o da inevitabilidade do uso imediatista dos recursos naturais" (VIOLA; FRANCHINI; RIBEIRO, 2013, p. 291).

$\mathrm{Na}$ contramão da tendência de queda dos anos anteriores, houve um aumento da taxa de desmatamento da Amazônia Legal a partir de 2013. De acordo com o relatório publicado pelo InfoAmazônia (2015), a entrada em vigor do novo Código Florestal brasileiro (Lei n. 12.651/2012), a redução de unidades de conservação da natureza para a construção de hidrelétricas na região do Tapajós ${ }^{21}$, a paralização da demarcação de terras indígenas e a pauperização dos órgãos ambientais são alguns dos fatores responsáveis por esse aumento.

Em 2016, ano inicial da quarta fase do PPCDAm, o desmatamento na Amazônia Legal foi de $7.983 \mathrm{~km}^{2}$, gerador de um acréscimo de $29 \%$ em relação a 2015 , quando $6.207 \mathrm{~km}^{2}$ foram desmatados. Conforme argumento do ministro do Meio 
A atuação do poder judiciário brasileiro nos biomas amazônia e cerrado visando combater o aquecimento global

Ambiente, uma série de elementos colaborou para esse índice, entre eles, problemas de gestão, uma transição de governo e a repercussão de três anos de mudança no Código Florestal (OBSERVATÓRIO DO CLIMA, 2017).

Outro fator que impacta no desempenho do PPCDAm é que o plano não detém "autoridade orçamentária", o seu orçamento federal não é vinculado ou obrigatório, o que justifica a existência de variações entre os valores autorizados e efetivamente investidos na execução das ações em todas as suas fases (ABDALA, 2015, p. 22). Fora isso, o plano tem sofrido cortes de orçamento. Como ilustração, destaca-se que entre os anos de 2007 e 2010, cerca de R\$ 6,4 bilhões foram investidos no PPCDAm; em contrapartida, tem-se um investimento de apenas $\mathrm{R} \$ 1,8$ bilhão entre os anos de 2011 e 2014, o que representa uma redução de aproximadamente $72 \%$ entre esses períodos (INFOAMAZÔNIA, 2015).

Por último, cabe relembrar que o PPCDAm já estava em sua segunda fase de execução (2009-2011) quando foi cooptado pela PNMC, o que indica que a meta de redução poderia ter sido mais ousada. Também nesse sentido, menciona-se que o lapso temporal considerado (1996-2005) para determinar a média de desmatamento (19.625 $\mathrm{km}^{2}$ ) sobre a qual incidiria o percentual de redução (80\%) abarca três dos cinco maiores índices de desmatamento já registrados na Amazônia Legal desde 1988, quando os monitoramentos foram iniciados ${ }^{22}$.

A despeito desse contexto, verifica-se que o PPCDAm objetivamente tem se aproximado ano a ano da meta de redução estabelecida em lei, sobretudo - volta-se a mencionar - porque é um plano cuja execução foi iniciada ainda em 2004, ou seja, cinco anos antes da entrada em vigor da PNMC. Globalmente considerado, o PPCDAm é um caso de sucesso da iniciativa pública do Brasil, de modo que no período entre 2004 e 2016 foram reduzidos aproximadamente $70 \%$ do desmatamento na Amazônia Legal.

Partindo-se dessa observação, convém analisar o Plano de Ação para a Prevenção e Controle do Desmatamento e das Queimadas no Cerrado e sua meta de redução de $40 \%$ dos índices anuais de desmatamento em relação à média verificada entre os anos de 1999 e 2008. 


\subsection{O PLANO DE AÇÃO PARA A PREVENÇÃO E CONTROLE DO DESMATAMENTO E DAS QUEIMADAS NO CERRADO (PPCerrado)}

Ambicionando o controle das queimadas e do desmatamento no bioma Cerrado, a PNMC instituiu o Plano de Ação para a Prevenção e Controle do Desmatamento e das Queimadas no Cerrado (PPCerrado), que, assim como o PPCDAm, é um plano setorial eminentemente regional sob a coordenação do Ministério do Meio Ambiente (MMA).

Do mesmo modo como ocorre com o PRODES desde 1988 em relação à Amazônia Legal, o bioma Cerrado passou a fazer parte do Projeto de Monitoramento do Desmatamento dos Biomas Brasileiros por Satélite (PMDBBS), pertencente ao Instituto Brasileiro do Meio Ambiente e dos Recursos Naturais Renováveis (IBAMA), a partir de 2008. Assim, em março de 2011 foi publicado pelo PMDBBS o Monitoramento do Bioma Cerrado 2008-2009 e, em agosto daquele mesmo ano, o Monitoramento do Bioma Cerrado 2009-2010. Apenas no final de 2015 foram estimados os números do desmatamento do Cerrado referentes ao período de 2010-2011, os últimos dados oficiais disponíveis.

De acordo com o Anexo do Decreto Legislativo n. 7.390/2010, objetiva o PPCerrado a redução de $40 \%$ dos índices anuais de desmatamento no bioma Cerrado em relação à média verificada entre os anos de 1999 a 2008. Nesse sentido, tem-se que a taxa de desmatamento média verificada no Cerrado entre os anos de 1999 e 2008 foi de $15.700 \mathrm{~km}^{2}$. A partir desse dado, tem-se que o desmatamento no bioma deve ser reduzido em $6.280 \mathrm{~km}^{2}$, anualmente, a partir da entrada em vigor da PNMC. Dito de outra forma, permite-se no Cerrado uma taxa de desmatamento igual ou inferior a 9.420 $\mathrm{km}^{2}$ ao ano.

Na sequência, é de particular interesse desta pesquisa os números oficiais das áreas desmatadas em destaque, indicadores do desempenho do PPCerrado a partir da vigência da PNMC. São eles:

Quadro 3 - Desmatamento no bioma Cerrado

\begin{tabular}{|c|c|}
\hline Área total do bioma Cerrado & $2.039 .386 \mathrm{~km}^{\mathbf{2}}$ \\
\hline Área desmatada antes de 2002 & $890.636 \mathrm{~km}^{\mathbf{2}}$ \\
\hline Área desmatada no período 2002-2008 & $85.074 \mathrm{~km}^{2}$ \\
\hline Área desmatada no período 2008-2009 & $7.637 \mathrm{~km}^{\mathbf{2}}$ \\
\hline Área desmatada no período 2009-2010 & $\mathbf{6 . 4 6 9} \mathbf{k m}^{\mathbf{2}}$ \\
\hline Área desmatada no período 2010-2011 & $\mathbf{7 . 2 4 7} \mathbf{k m}^{\mathbf{2}}$ \\
\hline
\end{tabular}


A atuação do poder judiciário brasileiro nos biomas amazônia e cerrado visando combater o aquecimento global

\begin{tabular}{|c|c|}
\hline Área total de desmatamento & $997.063 \mathrm{~km}^{2}$ \\
\hline Desmatamento sobre a área total & $48,89 \%$ \\
\hline
\end{tabular}

Fonte: MMA, 2015, p. 9 (grifo nosso)

Assim, entre 2008 e 2009, a área desmatada foi de $7.637 \mathrm{~km}^{2}$. Entre 2009 e 2010, por conseguinte, o desmate foi de $6.469 \mathrm{~km}^{2}$. Ora, se a meta era reduzir $40 \%$ do desmatamento, alcançando-se uma área igual ou inferior a $9.420 \mathrm{~km}^{2}$ ao ano, pode-se concluir que o PPCerrado, cuja primeira fase de execução teve início no ano de 2010, já entrou em vigor com a sua meta de redução plenamente atingida.

Em outras palavras, comparando a proximidade das datas dos resultados do IBAMA com a publicação da PNMC e do Anexo do Decreto Legislativo n. 7.390/2010, nota-se que a meta do PPCerrado nasceu virtualmente inexistente, isto é, foi cumprida antes mesmo de ser estabelecida. A esse respeito, posicionou-se o Greenpeace brasileiro ao afirmar que, na ocasião, “[...] o plano obteve uma redução de 60,5\% (quando a meta era de $40 \%$ ), e o excesso foi atingido sem que o governo tenha feito nada - só com base em uma falsa premissa de cálculo" (GREENPEACE BRASIL, 2013, p. 15). Nessa perspectiva, conclui-se que também aqui a meta poderia ter sido mais ousada.

No biênio seguinte (2010-2011), 7.247 km² foram desmatados no bioma. Apesar do acréscimo em relação ao período anterior (2009-2010), o PPCerrado seguiu superando o objetivo estabelecido em lei, atingindo em torno de $46 \%$ de redução do desmate por ano. Em que pese o incremento de aproximadamente $800 \mathrm{~km}^{2}$ de novas áreas desmatadas entre os anos de 2009 e 2011, nota-se, oficialmente, o cumprimento integral da meta fixada para o Plano.

Depreende-se, nesse sentido, que os resultados satisfatórios obtidos pelo PPCerrado nos primeiros anos de vigência da PNMC, antes de serem compreendidos como esforços conjuntos voltados para a efetiva proteção do bioma, derivam da manutenção estratégica de práticas habituais em curso no Cerrado. A corroborar com essa inferência, em comparação com a Amazônia, verifica-se que a legislação brasileira - e não apenas a PNMC - é muito mais permissiva em relação ao Cerrado. Na política climática, enquanto o PPCDAm objetiva a redução de $80 \%$ do desmate anual, o PPCerrado intenciona a metade desse valor, $40 \%$. Na lei federal de crimes ambientais ${ }^{23}$, a proteção é dedicada às florestas, inexistindo menção às demais formas de vegetação. Ainda, na lei federal que dispõe acerca da proteção da vegetação nativa brasileira ${ }^{24}$, enquanto proprietários rurais amazônicos devem conservar $80 \%$ da cobertura vegetal 
em suas terras, o percentual mínimo obrigatório no Cerrado é de 20\% (ALVARENGA, 2013. p. 47). Por fim, ainda que as taxas de desmatamento no Cerrado se assemelhem às da Amazônia (apesar daquele ter a metade da área desta) (MMA, 2014, p. 30), há outro “[...] sintoma, não desprezível, da 'invisibilidade' do Cerrado” (ALVARENGA, 2013, p. 41): a ausência de monitoramento preciso, anual e atualizado de sua cobertura vegetal, aos moldes do que ocorre no bioma amazônico. Como mencionado, as informações mais recentes a respeito do desmatamento no Cerrado datam de 2010-2011 e foram divulgadas no término de 2015.

Por essa razão, pode-se afirmar que o monitoramento das emissões de GEE no Cerrado também é "deficiente" e impreciso, pois “[...] a ausência dos dados anualizados impossibilita a análise das tendências e variações" (OBSERVATÓRIO DO CLIMA, 2015, p. 11). Para obtenção de cálculos aproximados, o valor do último ano disponível de desmatamento para o bioma é replicado nos anos seguintes. Desse modo, de 1990 a 2013, 21\% das emissões brasileiras de GEE foram diretamente geradas pelas queimadas e pelo desmatamento no Cerrado, resultando na emissão de 261 milhões de $\mathrm{tCO}_{2}$ eq por ano (OBSERVATÓRIO DO CLIMA, 2015, p. 7). De toda sorte, após a execução da primeira e segunda fases do plano - entre 2010-2011 e 2014-2015, respectivamente (e a institucionalização de um hiato entre 2012-2013), o PPCerrado ingressou em sua terceira fase a partir de 2016. Entre seus objetivos até 2020, estão a implementação de um sistema de detecção do desmatamento em tempo real e o mapeamento anual do bioma (MMA, 2016, p. 11).

Do exposto, diante das metas - em vias de alcance (Amazônia Legal) e até superadas (Cerrado) - da PNMC, demandantes de pouca mobilização do Poder Público e, ainda, do baixo potencial de proteção jurídica conferido especialmente ao bioma Cerrado, constatar-se-á que a performance brasileira na redução de suas emissões de GEE poderia ser desenvolvida em escala distinta, com propósitos que significassem empenho e compromisso fidedignos com a diminuição dos efeitos danosos das mudanças do clima. Por esse motivo, interessa a análise da atuação do Poder Judiciário nessa seara, de modo a verificar se a postura adotada pelos magistrados representa ou não um diferencial no trato climático praticado atualmente no Brasil. É o que se faz a seguir. 
A atuação do poder judiciário brasileiro nos biomas amazônia e cerrado visando combater o aquecimento global

\section{O CARÁter Simbólico da PNMC E A ATUAÇÃo dO PODER JUDICIÁRIO BRASILEIRO NOS BIOMAS AMAZÔNIA E CERRADO VISANDO COMBATER OS EFEITOS DO AQUECIMENTO GLOBAL}

Após a análise dos resultados obtidos pelo PPCDAm e pelo PPCerrado, a presente pesquisa volta-se novamente à Política Nacional sobre Mudança do Clima e sua meta de reduzir entre $36,1 \%$ e $38,9 \%$ as emissões de GEE do país projetadas até 2020. Conforme mencionado anteriormente, a projeção das emissões brasileiras de GEE para o ano de 2020 é de 3.236 milhões de $\mathrm{tCO}_{2} \mathrm{eq}$, sendo composta pelas emissões de distintos setores ${ }^{25}$, conforme representado no gráfico a seguir.

Gráfico 1 - Emissões projetadas por setor

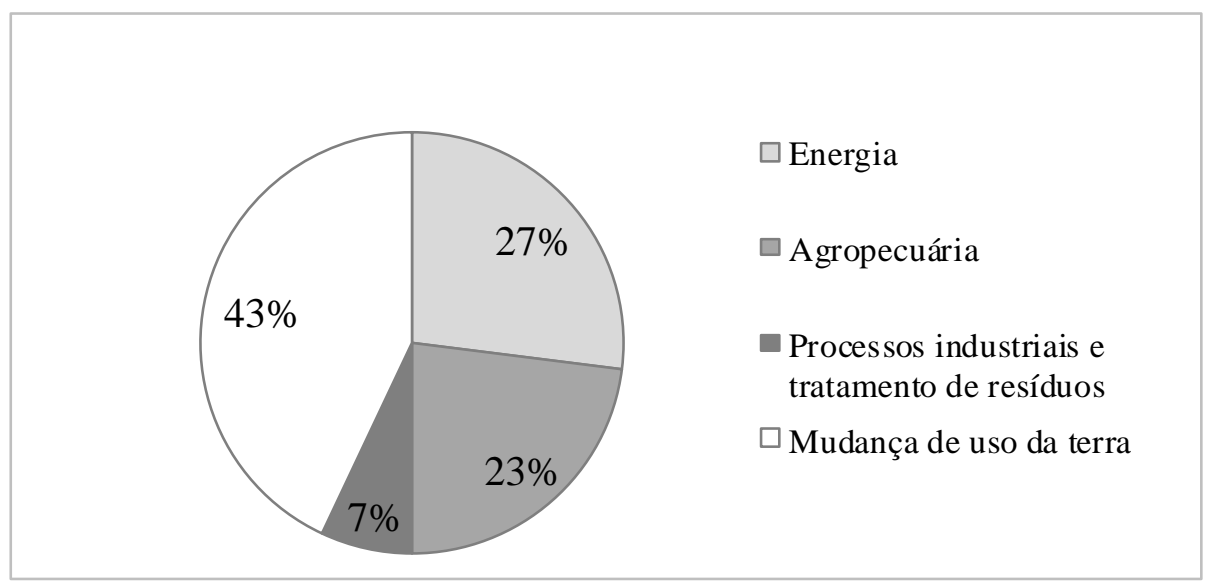

O total de emissões projetadas para o setor de mudança de uso da terra é de 1.404 milhões de $\mathrm{tCO}_{2} \mathrm{eq}^{26}$, o que corresponde a aproximadamente $43 \%$ do volume integral das emissões projetadas para 2020. Tanto o PPCerrado como o PPCDAm encontram-se inseridos nesse contexto. É oportuno mencionar que o desmatamento da Amazônia Legal representa, isoladamente, 29\% dessas emissões; por sua vez, cerca de $10 \%$ dessas emissões provêm do bioma Cerrado $^{27}$.

Posto isso, acrescenta-se que ao estabelecer uma meta de redução entre $36,1 \%$ e $38,9 \%$ do total de emissões projetadas para 2020, ou seja, de 3.236 milhões de $\mathrm{tCO}_{2} \mathrm{eq}$, o Brasil comprometeu-se a reduzir as suas emissões de GEE entre 1.168 e 1.259 milhões de $\mathrm{tCO}_{2}$ eq até 2020, o que deve se refletir em cada um dos setores acima indicados. Com base nesses dados, retoma-se a análise do PPCDAm e do PPCerrado, inserindo-os no panorama apresentado. 
O PPCDAm, convém relembrar, tem como meta a redução de $80 \%$ dos índices anuais de desmatamento amazônico em relação à média verificada entre os anos de 1996 e 2005. Essa média é de $19.625 \mathrm{~km}^{2}$ e corresponde, em termos de emissões projetadas, a 952 milhões de $\mathrm{tCO}_{2} \mathrm{eq}^{28}$. Cabe ao PPCDAm, portanto, promover uma redução de 761,6 milhões de $\mathrm{tCO}_{2}$ eq das emissões projetadas na Amazônia Legal a cada ano. Nos anos de 2012 e 2014, este valor foi praticamente alcançado, correspondendo, respectivamente, a 733 e 704,5 milhões de $\mathrm{tCO}_{2}$ eq.

Ao PPCerrado, por sua vez, foi atribuída a meta de redução de $40 \%$ dos índices anuais de desmatamento no bioma em relação à média verificada entre os anos de 1999 a 2008. Essa média foi de $15.700 \mathrm{~km}^{2}$, o que equivale, em termos de emissões projetadas, a 322.9 milhões de $\mathrm{tCO}_{2} \mathrm{eq}^{29}$. Seguindo o mesmo raciocínio aplicado ao PPCDAm, cabe ao PPCerrado promover uma redução de 129,1 milhões de $\mathrm{tCO}_{2}$ eq das emissões projetadas no bioma a cada ano. Observou-se, com base nos últimos dados oficiais disponíveis, que entre 2009 e 2010 houve uma redução de 58,7\% em relação à média verificada entre os anos de 1999 e 2008, o que equivale a 189,5 milhões de $\mathrm{tCO}_{2}$ eq. Entre 2010 e 2011, de acordo com os últimos dados oficiais disponíveis, a redução foi de $46 \%$ em relação à média, pouco mais de 170 milhões de $\mathrm{tCO}_{2}$ eq.

Somando-se, portanto, os índices alcançados pelo PPCDAm e pelo PPCerrado no ano de 2010, tem-se uma redução de 798,8 milhões de $\mathrm{tCO}_{2} \mathrm{eq}$, o que equivale a $68 \%$ da meta mínima $(36,1 \%)$ estabelecida pela PNMC. Dito isso, relembrase que o setor de mudança de uso da terra representa $43 \%$ do total de emissões projetadas para $2020^{30}$. Isso significa que os setores de energia, agropecuária e processos industriais e tratamento de resíduos, apesar de responderem juntos por $57 \%$ das emissões projetadas para 2020, teriam como meta uma redução de aproximadamente $32 \%$.

Isoladamente, no ano de 2012, quando obteve o seu melhor resultado, o PPCDAm representou $62,7 \%$ da meta mínima $(36,1 \%)$ de redução estabelecida pela Política Nacional sobre Mudança do Clima. Nesse sentido, verifica-se que o PPCDAm é responsável, em separado, pelos índices satisfatórios que vêm sendo obtidos pela PNMC desde a sua entrada em vigor e, nesse horizonte, percebe-se que tem funcionado como uma espécie de anteparo dos demais planos no resultado da política climática em curso no Brasil. 
A atuação do poder judiciário brasileiro nos biomas amazônia e cerrado visando combater o aquecimento global

Ainda que a Política Nacional sobre Mudança do Clima seja considerada representante da "[...] vanguarda legislativa do Direito Ambiental brasileiro" (SARLET; FENSTERSEIFER, 2014, p. 280), em verdade, está-se diante de uma legislação cuja dimensão simbólica expressa-se por meio da adoção de um compromisso internacional voluntário que, apesar de politicamente significativo, não representa propriamente um desafio para o país.

Acrescenta-se a isso fato de ser a PNMC uma lei desprovida de caráter sancionatório. E é justamente por se tratar de uma mera proclamação de intenções que a atuação do Poder Judiciário, assim como o protagonismo da sociedade civil em parceria com as entidades do terceiro setor, se mostram indispensáveis no sentido de exigir maior seriedade do governo brasileiro ao tratar das questões climáticas em âmbito nacional (NALINI, 2010, p. 6).

Diante da postura brasileira de adotar um discurso e praticar o inverso, propagandeando metas cujo alcance independe de esforços nacionais genuínos, verificar-se-á, adiante, se o Poder Judiciário brasileiro tem se mostrado sensível à causa ecológica, atuando no sentido de assegurar as condições mínimas para a preservação dos atributos ecológicos dos biomas Amazônia e Cerrado face às mudanças climáticas.

\subsection{ANÁLISE DE JULGADOS QUE ENVOLVEM A QUESTÃO CLIMÁTICA E} A MANUTENÇÃO DO BIOMA AMAZÔNIA

Uma vez demonstrado que as metas estabelecidas pela PNMC independem de incentivos concretos por parte do Brasil, pretende-se, neste momento, verificar a apreciação judicial do tema, evidenciando a imprescindibilidade do Poder Judiciário no que tange à eficácia na adoção de medidas de mitigação e adaptação às consequências das alterações climáticas no bioma amazônico.

Deste modo, realizou-se uma pesquisa jurisprudencial no repositório do Superior Tribunal de Justiça (STJ), responsável pela uniformização das leis federais no Brasil, assim como nos Tribunais de Justiça dos estados federativos que compõem a chamada Amazônia Legal ${ }^{31}$. Com o intuito de localizar decisões que relacionam, de forma expressa, a Amazônia Legal às mudanças climáticas, a busca restringiu-se ao acervo de julgados publicados a partir do dia 29 de dezembro de 2009, data de promulgação da PNMC. Da mesma forma, a pesquisa primou pela conjugação de termos/expressões vinculados ao tema, possibilitando, assim, uma análise detida do 
assunto. Nesse sentido, com o propósito de identificar a Amazônia Legal, foram utilizados os seguintes termos/expressões: Amazônia, Floresta Amazônica, desmatamento e desflorestamento. Para detectar as mudanças climáticas decorrentes do aquecimento global, por sua vez, recorreu-se aos seguintes termos/expressões: mudanças climáticas, aquecimento global, efeito estufa, GEE e Lei 12.187/2009 (Política Nacional sobre Mudança do Clima). Assim, da combinação dos termos e das expressões ora mencionados derivaram 20 arranjos passíveis de resultados.

Diante da investigação jurisprudencial realizada no STJ, ainda que em seu oitavo ano de vigência, verificou-se a inexistência de quaisquer menções à PNMC, assim como de decisões que vinculem, de forma declarada, a Amazônia Legal às mudanças climáticas. Nesse sentido, até o presente momento, não há indícios de que a corte superior brasileira esteja atuando no bioma amazônico com o propósito específico de combater os efeitos do aquecimento global.

Observa-se, por outro lado, que foram encontradas 8 decisões monocráticas ${ }^{32}$ em que o uso dos termos/expressões em questão ocorre em uma acepção técnica, pautada tão somente na questão terminológica, pontuando a relevância do tema no contexto atual, sem, todavia, correlacionar o desmatamento do bioma amazônico às mudanças climáticas. Quer dizer, os julgamentos referem-se ao tema de forma genérica, considerando apenas o estado ambiental corrente, sem ponderar as causas e efeitos das mudanças climáticas e a estreita relação existente entre elas e os casos submetidos à apreciação do Poder Judiciário ${ }^{33}$.

Nesse lanço, e considerando-se que a preocupação dos magistrados com o fenômeno das mudanças climáticas é ainda incipiente, convém mencionar que, de acordo com Recondo (2017), o tempo médio de tramitação de demandas postuladas no Poder Judiciário brasileiro - primeira e segunda instâncias - gira em torno de 5 anos. A esse período, soma-se o prazo aproximado de 3 anos, tempo que um processo demora para transitar em julgado no STJ. Desta maneira, uma ação judicial que chega a um dos órgãos máximos do Poder Judiciário brasileiro leva em média 8 anos para ser devidamente solucionada. Logo, na consideração desse decurso estimado e do oitavo ano de vigência da PNMC, torna-se compreensível que as questões que permeiam as mudanças climáticas ainda estejam engatinhando na corte superior brasileira.

Posto isso, foram pesquisados os Tribunais de Justiça dos noves estados pertencentes à Amazônia Legal, podendo-se afirmar que em nenhum deles o R. Fac. Dir. UFG, v. 42, n. 2, p.11-47, maio/ago. 2018 
A atuação do poder judiciário brasileiro nos biomas amazônia e cerrado visando combater o aquecimento global

desmatamento foi relacionado de forma direta à temática das mudanças climáticas. Ao contrário, as menções sobre o tema são sempre pontuais e sem quaisquer aprofundamentos. A título exemplificativo, alguns dos resultados obtidos a partir da conjugação da expressão mudança climática descrevem apenas o tempo meteorológico - o estado atmosférico local e imediato, e, portanto, em um significado restrito - a impactar a agricultura de uma determinada região, como no caso analisado pelo Tribunal de Justiça de Roraima ${ }^{34}$. Não se pode perder de vista que as mudanças climáticas, especialmente no contexto ora pesquisado, são consideradas em escala distinta: não como tempo, mas sim como clima. Ou seja, um fenômeno que tende a ser geral e duradouro, oriundo do somatório de inúmeros eventos meteorológicos, considerados inicialmente em décadas ou até mesmo em séculos (STEINKE, 2012, p. 17).

Merece destaque, no entanto, a publicação do Acórdão n. 77.680 pelo Tribunal de Justiça do Pará (BRASIL. TJPA, 2009) pouco antes da promulgação da PNMC, que, ao abordar o cancelamento de licenças de exploração madeireira na região amazônica, afirma que:

[...] não se pode deixar de levar em consideração o prejuízo que toda a sociedade sofreria com a exploração irregular das madeiras, que agravaria, ainda mais, os sérios danos ambientais provenientes da utilização incorreta da exploração dos recursos naturais, tais como asseveramento de desmatamento, poluição, proliferação de doenças pulmonares, contribuição para o aquecimento global, mortandade em massa da biodiversidade do patrimônio genético de nossas florestas, sobretudo, da floresta amazônica, considerada a possuidora da maior biodiversidade do planeta (grifo nosso).

Não menos importante, frisa-se a decisão proferida pelo Tribunal de Justiça do Mato Grosso (BRASIL. TJMT, 2007), também anterior à PNMC, que versa sobre o reconhecimento da inconstitucionalidade de dispositivo do Código Ambiental Estadual que previa a possibilidade de compensação pecuniária pelo desmatamento de áreas protegidas situadas no Estado do Mato Grosso, nos termos da Lei Complementar n. 232/2005, conforme segue:

[...] hoje tenho uma visão diferente a respeito do tema ora em debate; essa mudança de enfoque tem a ver com a conjuntura por que passa o nosso planeta, com o aquecimento global, levando-nos a uma séria reflexão. Nos últimos dias temos visto muitas notícias a respeito da degradação do meio ambiente no mundo e, em relação ao Estado de Mato Grosso, a constatação de que foi o estado que mais contribuiu para o 
desmatamento da região amazônica (não nos esqueçamos que fazemos parte da Amazônia Legal); por esta e por outras razões não posso deixar de concordar com o Meritíssimo Juiz do feito quando, entusiasticamente, defende o meio ambiente, tanto quanto não posso deixar de reconhecer que todos dependemos dele para que tenhamos uma vida saudável. [...] reconhecer que a solução aventada pelo Estado de Mato Grosso, através da Lei Complementar n. 232/2005, para compensar o desmatamento, é, sim, $a$ priori, marcadamente inconstitucional, haja vista que não pode se dar pelo pagamento em dinheiro; se assim se permitir, daqui a poucos anos, talvez o estado tenha muito dinheiro em caixa, mas terá contribuído decisivamente para a crescente desertificação do território mato-grossense (grifo nosso).

Pelo exposto, excetuada as decisões acima referidas, os temas que permeiam a PNMC no âmbito do bioma amazônico possuem tratamento variado nos poucos julgados em que aparecem, apresentando acepções e significações diversas. Cabe registrar que os julgamentos acabam por fazer uma referência genérica ao tema como forma de contextualizar o estado atual do ambiente, as ameaças e agressões existentes, não havendo uma reflexão apropriada sobre as causas e efeitos das mudanças climáticas e a estreita relação existente entre elas e os casos submetidos à apreciação do Poder Judiciário.

Enfim, conquanto a inclusão de variáveis relacionadas às mudanças climáticas e ao desmatamento da Floresta Amazônica nas decisões judiciais ainda seja embrionária, a apuração dos julgados nos Tribunais de Justiça dos estados federativos que compõem o bioma Cerrado mostrará uma avaliação auspiciosa sobre o tema, sobretudo em razão da queima da palha da cana-de-açúcar, prática comum em diversas regiões do país e geradora de significativas emissões de GEE na atmosfera.

\subsection{ANÁLISE DE JULGADOS QUE ENVOLVEM A QUESTÃO CLIMÁTICA E A MANUTENÇÃO DO BIOMA CERRADO}

Com o intuito de analisar a receptividade do Poder Judiciário em relação à preservação do equilíbrio ecológico no bioma Cerrado face às alterações do clima decorrentes do aquecimento global, também se realizou uma investigação de jurisprudência no acervo do STJ, bem como nos Tribunais de Justiça dos estados federativos que integram áreas do Cerrado ${ }^{35}$. Objetivando a localização de julgados que vinculem, explicitamente, o Cerrado às mudanças climáticas, a pesquisa amparou-se na coletânea de julgados publicada a partir do dia 29 de dezembro de 2009, data em que a PNMC foi instituída. Igualmente, a busca primou pela conjugação de termos/expressões 
A atuação do poder judiciário brasileiro nos biomas amazônia e cerrado visando combater o aquecimento global

vinculados ao tema, possibilitando, assim, uma análise detida do assunto. Nesse sentido, com o propósito de identificar o Cerrado, foram utilizados os seguintes termos/expressões: Cerrado, queimadas, desmatamento e desflorestamento. Para detectar as mudanças climáticas decorrentes do aquecimento global, recorreu-se aos seguintes termos/expressões: mudanças climáticas, aquecimento global, efeito estufa, GEE e Lei 12.187/2009 (Política Nacional sobre Mudança do Clima). Logo, da combinação dos termos e das expressões ora mencionados, derivaram 20 arranjos passíveis de resultados.

Da mesma forma que a apuração jurisprudencial realizada no STJ com relação ao bioma Amazônia, verificou-se a inexistência de quaisquer menções à PNMC, assim como de decisões que vinculem diretamente o Cerrado às mudanças climáticas, ainda que em seu oitavo ano de vigência. Novamente, convém lembrar que uma ação judicial que chega a um dos órgãos máximos do Poder Judiciário brasileiro leva em média 8 anos para ser devidamente solucionada e arquivada em caráter definitivo. Contudo, oportuno mencionar que da combinação dos termos queimadas e mudanças climáticas resultou o Informativo de Jurisprudência n. 0449, publicado pela corte superior brasileira no ano de 2010, que assim dispõe:

[...] as queimadas, principalmente promovidas pela atividade agrícola, são incompatíveis com os objetivos de proteção do meio ambiente estabelecidos pelo ordenamento jurídico, quanto mais em época de mudanças climáticas, quando qualquer exceção a essa proibição geral deve ser interpretada restritivamente pelo administrador e pelo juiz (grifo nosso).

Conforme precedente assentado pelo STJ, as mudanças climáticas justificam uma interpretação restritiva das regras excepcionais permissivas de queimadas constantes na legislação federal, principalmente em virtude da queima da palha da canade-açúcar.

A esse respeito, assinala-se que a queima da palha da cana-de-açúcar é realizada antes de sua colheita e objetiva a eliminação, por combustão, de toda matéria vegetal que não apresenta serventia, evitando, assim, o transporte desnecessário de substâncias inaproveitáveis do canavial para as usinas refinadoras. Busca-se, em suma, a otimização da colheita e da produção industrial (COSTA, 2013). De fato, o artigo 38 do novo Código Florestal $^{36}$ proíbe o uso de fogo na vegetação ${ }^{37}$, exceto em locais ou regiões cujas peculiaridades justifiquem a aplicação de queimadas em atividades 
agropastoris ou florestais, mediante prévia autorização do órgão estadual competente. O emprego do fogo para fins de queima controlada, portanto, configura prática expressamente admitida e regulada pela legislação ambiental brasileira.

Apesar disso, o tema passou a ser considerado nas demandas que versam sobre a prática de desmate mediante utilização de fogo. Nesse sentido, menciona-se acórdão proferido pelo STJ (BRASIL. STJ, 2009) em que o Ministro Humberto Martins, ao fundamentar seu voto, valeu-se de informações de diversas ciências relacionadas à área ambiental, que, dada a pertinência, cabe transcrever:

\begin{abstract}
Alega-se em defesa às queimadas que, embora haja uma forte liberação de $\mathrm{CO}_{2}$, este gás não contribui - em médio prazo - para o dito efeito estufa, pois uma quantidade equivalente dele é retirada da atmosfera, via fotossíntese, durante o crescimento do canavial no ano seguinte. Esta argumentação é válida e correta, senão por um pequeno diferencial nunca explicitado: o canavial realmente absorve e incorpora $\mathrm{CO}_{2} \mathrm{em}$ grande quantidade, ao longo do seu período de crescimento que dura de 12 a 18 meses em média, e a queimada libera tudo quase que instantaneamente, ou seja, no período que dura uma queimada, ao redor de 30 ou 60 minutos. Portanto, libera $\mathrm{CO}_{2}$ recolhido da atmosfera durante 12 a 18 meses em pouco mais de 30 ou 60 minutos. Além disso, junto com o $\mathrm{CO}_{2}$, outros gases são formados e lançados na atmosfera. Dentre o coquetel de substâncias químicas nocivas que são lançadas na atmosfera, durante a queima da cana, destacam-se os hidrocarbonetos aromáticos policíclicos (grifo nosso).
\end{abstract}

Concluída essa etapa, foram pesquisados os Tribunais de Justiça dos 14 estados cujas áreas integram o Cerrado, podendo-se afirmar que em nenhum deles o desmatamento foi relacionado de forma direta à temática das mudanças do clima, com a exceção do Tribunal de Justiça de São Paulo (TJSP), que vem efetivamente considerando a questão climática como fundamento para decisões enunciadas.

Isso porque o estado de São Paulo promulgou, também em 2009, legislação estadual específica para o enfrentamento das alterações do clima em razão do aquecimento global. Trata-se da Lei Estadual n. 13.798, que instituiu a Política Estadual de Mudanças Climáticas (PEMC) e tem por escopo "[...] estabelecer o compromisso do Estado frente ao desafio das mudanças climáticas globais, dispor sobre as condições para as adaptações necessárias aos impactos derivados das mudanças climáticas, bem como contribuir para reduzir ou estabilizar a concentração dos GEE na atmosfera" ${ }^{2}$.

Impende observar que a PEMC, além de elencar princípios ambientais, fixou objetivos ${ }^{39}$ e diretrizes ${ }^{40}$ regulados por meio de um instrumento chamado Avaliação Ambiental Estratégica do processo de desenvolvimento setorial ${ }^{41}$, cujo R. Fac. Dir. UFG, v. 42, n. 2, p.11-47, maio/ago. 2018 
A atuação do poder judiciário brasileiro nos biomas amazônia e cerrado visando combater o aquecimento global

propósito é analisar, de forma sistemática, as consequências ambientais de políticas, planos e programas públicos e privados, frente aos desafios das mudanças climáticas.

Não menos importante, o TJSP instaurou, em 2005, a Câmara Reservada ao Meio Ambiente, colegiado composto por desembargadores especializados em Direito Ambiental que trouxe maior celeridade e melhor aparelhamento dos setores encarregados pelo julgamento de demandas ambientais (NALINI, 2010, p. 11).

Assim posta a questão, merece destaque a publicação do Acórdão n. 0002727-40.2008.8.26.0619 pelo TJSP (BRASIL. TJSP, 2013), que, ao abordar o responsabilização ambiental em razão da queima controlada da palha da cana-de-açúcar, assim dispõe:

\begin{abstract}
Cabe ainda tecer considerações sobre o dano ambiental determinado no caso concreto $\mathrm{e}$, neste sentido, merece menção a legislação referente às "mudanças climáticas". A importância do tema levou à promulgação pelas três esferas de Governo de normas referentes às "mudanças climáticas" (respectivamente, Leis nos. 12.187/09, 13.798/09 e 14.933/09), em sintonia com as preocupações externadas na Rio-92 e no Tratado de Quioto. Cada vez mais, as conclusões científicas apontam as intensas emissões de carbono como uma das mais prováveis causas do aquecimento do planeta. No caso brasileiro, as queimadas ganham destaque como principal fator de emissão deste gás na natureza, chegando a $75 \%$ da poluição total, segundo dados do IBGE. Em suma, poluir a natureza exige a responsabilização civil da parte, sendo plenamente aplicável na espécie a teoria do risco integral (grifo nosso).
\end{abstract}

Constatou-se a existência de mais 18 Acórdãos $^{42}$ proferidos pela Câmara Reservada ao Meio Ambiente, todos elaborados pelo Relator João Negrini Filho, que relacionam explicitamente as queimadas da palha de cana-de-açúcar no bioma Cerrado às mudanças climáticas, fazendo não apenas menção expressa à PNMC, mas também à PEMC e à Política Municipal de Mudança do Clima de São Paulo (Lei Municipal n. $14.933 / 2009)$.

Ainda, outras sentenças tendo como objeto a proibição da queima controlada da palha de cana-de-açúcar no Cerrado paulista levam em consideração as consequências do desenvolvimento dessa atividade para "as mudanças na atmosfera relacionadas ao efeito estufa e ao consequente aquecimento global" (BRASIL. TJSP, 2015): “[...] o efeito estufa, já sentido no Brasil, é agravado em virtude das queimadas” (BRASIL. TJSP, 2011). Nesse mesmo sentido, cita-se:

Não bastasse isso, em tempos nos quais se aprofundam os estudos acerca dos impactos da ação humana sobre o clima e o equilíbrio ecológico- 
planetário, já se podendo observar o início dos efeitos nocivos do aquecimento global, que se não for contido, segundo projeções, tende a ser catastrófico para a humanidade em longo prazo, as queimadas são indiscutivelmente ecologicamente reprováveis, pois é indiscutível sua contribuição para a liberação de carbono e da elevação da temperatura planetária (BRASIL. TJSP, 2014) (grifo nosso).

Pelo exposto, não há que se falar somente no cumprimento das metas de redução de emissões assumidas pelo Brasil com o advento da PNMC, mas sobretudo na incorporação dessa política nos julgados emanados pelo Poder Judiciário pátrio, tornando possível a apreciação de outras demandas que envolvem as mudanças climáticas - para além, por evidente, do nexo entre fogo e desmate -, como a implementação de fontes de energia limpa e o desenvolvimento de medidas de controle de tráfego e emissões veiculares. A complexidade das mudanças do clima e suas temáticas correlatadas carecem de análises técnicas multifacetadas e sistêmicas, correspondentes à exigência do apreço da questão ambiental.

\section{CONSIDERAÇÕES FINAIS}

Inobstante a importância da Amazônia e do Cerrado como regiões estratégicas para a conservação da diversidade biológica existente no planeta, evidenciou-se nesta pesquisa que o desmatamento desenfreado e o uso insustentável de queimadas nos respectivos biomas constituem uma das principais causas de emissões de GEE no Brasil e, portanto, pode-se afirmar que a mudança no uso da terra contribui significativamente para o fenômeno do aquecimento global.

Diante desse contexto, verificou-se que a implementação da ConvençãoQuadro das Nações Unidas sobre a Mudança do Clima pelo país culminou na elaboração da Política Nacional sobre Mudança do Clima (PNMC) que, internalizando um compromisso voluntário assumido perante a comunidade internacional, estabeleceu como meta a redução entre 36,1\% e 38,9\% das emissões brasileiras projetadas até 2020. Com esse propósito, elencou planos de ação para a prevenção e controle do desmatamento nos biomas e planos setoriais de mitigação e de adaptação às mudanças climáticas, todos integrantes do Plano Nacional sobre Mudança do Clima.

Dentre os planos de ação atualmente em andamento, além de se concluir que o PPCerrado entrou em vigor com a sua meta de redução plenamente atingida, constatou-se que o PPCDAm é responsável, isoladamente, pelos índices satisfatórios 
A atuação do poder judiciário brasileiro nos biomas amazônia e cerrado visando combater o aquecimento global

que vêm sendo alcançados pela PNMC. Observou-se que no ano de 2012, quando obteve o seu melhor resultado, o Plano representou a conquista de $62,7 \%$ da meta mínima $(36,1 \%)$ de redução de gases de efeito estufa estabelecida pela Política Nacional sobre Mudança do Clima. Assim sendo, ainda que o PPCDAm tenha funcionado como anteparo dos demais planos no exitoso cômputo da política climática brasileira, entendese que as metas de ambos os planos poderiam ter sido mais arrojadas.

Perante metas pouco expressivas, destacou-se que a PNMC remanesce como uma legislação cuja dimensão simbólica expressa-se por meio da adoção de um compromisso internacional voluntário que, apesar de politicamente significativo, não representa propriamente um desafio para o país. Dessa maneira, não há que se falar somente no cumprimento das metas de redução de emissões assumidas pelo Brasil com o advento da PNMC, mas na incorporação da regulação climática nos julgados emanados pelo Poder Judiciário pátrio.

A análise jurisprudencial realizada demonstrou que a inclusão de variáveis relacionadas às mudanças climáticas e ao desmatamento da Floresta Amazônica e do Cerrado nas decisões judiciais ainda é incipiente, tendo os temas que permeiam a PNMC no âmbito de ambos os biomas tratamento variado nos poucos julgados em que aparecem, apresentando interpretações diversas. Registrou-se que os julgamentos acabam por fazer uma referência generalista ao tema, inexistindo uma reflexão apropriada sobre as causas e efeitos das alterações do clima e, ainda, da estreita relação que estabelecem com os casos submetidos à análise do Poder Judiciário.

Reafirma-se, em arremate, que o Poder Judiciário tem o compromisso de fazer cumprir as normas expressas na Constituição Federal de 1988, a qual conferiu tratamento condigno e responsável à questão ambiental. Diante dessa constatação, reconhece-se que a proteção da Floresta Amazônica e do Cerrado é, portanto, um dever constitucional do qual não pode se esquivar o governo brasileiro, sobretudo porque condição indispensável para garantir a efetividade do direito fundamental ao ambiente ecologicamente equilibrado. Por essa razão, a natureza dos esforços empreendidos para assegurar a preservação dos biomas em face das mudanças climáticas deve obrigatoriamente refletir a urgência que o problema enseja. 


\section{REFERÊNCIAS}

ABDALA, G. C. Amazônia brasileira: desafios para uma efetiva política de combate ao desmatamento. Brasília: WWF Brasil, 2015.

ALVARENGA, L. J. A conservação do bioma Cerrado: o direito ante a fragmentação de ciências e ecossistemas. São Paulo: Annablume, 2013.

AMARAL, M. T.; VALE, R. C. S. Biodiversidade e mudanças climáticas: um olhar sobre a Amazônia. In: Enciclopédia Biosfera. Centro Científico Conhecer: Goiânia. v. 6, n. 11, 2010.

BORGES, L. C. R. Redução de emissões por desmatamento e degradação - REDD: desafios e oportunidades para o Brasil no contexto das mudanças climáticas. Dissertação de Mestrado. Universidade de Brasília (UnB): Centro de Desenvolvimento Sustentável (CDS), 2011.

BRADBROOK, A.; OTTINGER, R. Energy law and sustainable development. Genebra, Suíça: IUCN, 2003.

CADERNOS ADENAUER X. Amazônia e desenvolvimento sustentável. Rio de Janeiro: Fundação Konrad Adenauer, 2010.

CAPOBIANCO, J. P. R. (Org.). Biodiversidade na Amazônia Brasileira: avaliação e ações prioritárias para a conservação, uso sustentável, e repartição de benefícios. São Paulo: Instituto Socioambiental, 2001.

COSTA, M. L. O. A queima da palha da cana-de-açúcar no Estado de São Paulo. 2013. Disponível em: <http://www.migalhas.com.br/dePeso/16,MI180001,61044A+queima+da+palha+da+canadeacucar+no+Estado+de+Sao+Paulo>. Acesso em: 5 nov. 2017.

DUARTE, L. M. G.; THEODORO, S. H. (Orgs.). Dilemas do Cerrado: entre o ecologicamente (in)correto e o socialmente (in)justo. Rio de Janeiro: Garamond, 2002.

GREEnPEACE BRASIL. As lições da Política Nacional de Mudança do Clima. $2013 . \quad$ Disponível em: <http://www.greenpeace.org/brasil/Global/brasil/image/2013/Novembro/relatorio\%20p nmc\%20final.pdf>. Acesso em: 25 nov. 2017.

INFOAMAZÔNIA. A Política do Desmatamento. Disponível em: <http://desmatamento.infoamazonia.org/analise/>. Acesso em: 22 nov. 2017.

INSTITUTO DE PESQUISA AMBIENTAL DA AMAZÔNIA (IPAM). REDD no Brasil: um enfoque amazônico. Brasília, DF: Centro de Gestão e Estudos Estratégicos, 2011. 
A atuação do poder judiciário brasileiro nos biomas amazônia e cerrado visando combater o aquecimento global

INSTITUTO DO HOMEM E MEIO AMBIENTE DA AMAZÔNIA (IMAZON). EVOLUÇÃO DAS EMISSÕES DE GASES DE EFEITO ESTUFA NO BRASIL (1990-2013): Setor de Mudança de Uso da Terra. SEEG: Observatório do Clima, 2015.

INSTITUTO NACIONAL DE PESQUISAS ESPACIAIS (INPE). PRODES - taxas anuais de desmatamento - 1988 até 2016. Disponível em: <http://www.obt.inpe.br/prodes/taxas_prodes.htm>. Acesso em: 20 nov. 2017.

JURAS, L. A. G. M. Aquecimento global e mudanças climáticas: uma introdução. Brasília: Biblioteca Digital da Câmara dos Deputados, 2008.

LAVRATTI, P.; CAVEDON-CAPDEVILLE, F. de S. Política Nacional sobre Mudança do Clima. In: LEITE, J. R. M. (Coord.). Manual de Direito Ambiental. São Paulo: Saraiva, 2015.

LEAL-ARCAS, R. Climate change and international trade. Cheltenham, UK: Edward Elgar Publishing Limited, 2013.

MAZZUOLI, V. O; GALVÃO, S. M. A proteção internacional do meio ambiente no Tratado de Cooperação Amazônica. Revista dos Tribunais: Thomson Reuters, v. 909, jul. 2011.

MELLO-THÉRY, N. A.; THÉRY, H. Atlas do Brasil: disparidades e dinâmicas do território. São Paulo: USP, 2014.

MILARÉ, E. Direito do Ambiente: a gestão ambiental em foco: doutrina, jurisprudência, glossário. São Paulo: Revista dos Tribunais, 2011.

MINISTÉRIO DA AGRICULTURA, PECUÁRIA E ABASTECIMENTO. Projeções do agronegócio: Brasil 2012/13 a 2022/23. Brasília: MAPA, 2013.

MINISTÉRIO DO MEIO AMBIENTE (MMA). Monitoramento do Bioma Cerrado 2008-2009. Brasília: MMA, 2011.

MINISTÉRIO DO MEIO AMBIENTE (MMA). Plano de ação para prevenção e controle do desmatamento e das queimadas no Cerrado: $2^{\text {a }}$ fase (2014-2015). Brasília, MMA, 2014.

MINISTÉRIO DO MEIO AMBIENTE (MMA). Plano de ação para prevenção e controle do desmatamento no Cerrado: plano operativo 2016-2020. Brasília: MMA, 2016.

MINISTÉRIO DO MEIO AMBIENTE (MMA). Pantanal. Disponível em: <http://www.mma.gov.br/biomas/pantanal>. Acesso em: 20 set. 2017.

NALINI, J. R. As mudanças climáticas perante o Direito. 2010. Disponível em: <http://www.planetaverde.org/arquivos/biblioteca/arquivo_20131207160230_6927.pdf >. Acesso em: 30 nov. 2017. 
OBSERVATÓRIO DO CLIMA. Evolução das emissões de gases de efeito estufa no Brasil (1990-2013): setor de mudança de uso da terra. 2015. Disponível em: $<$ http://www.observatoriodoclima.eco.br/imazon-evolucao-das-emissoes-de-gases-deefeito-estufa-no-brasil-1990-2013-setor-de-mudanca-de-uso-da-terra/>. Acesso em: 28 nov. 2017.

OBSERVATÓRIO DO CLIMA. Desmatamento sobre 29\%, o maior em 8 anos. Disponível em: <http://www.observatoriodoclima.eco.br/desmatamento-sobe-29-omaior-em-8-anos/>. Acesso em: 3 nov. 2017.

PÁDUA, J. A. (Org.). Desenvolvimento, justiça e meio ambiente. São Paulo: Peirópolis, 2009.

PAINEL BRASILEIRO DE MUDANÇAS CLIMÁTICAS (PBMC). Contribuição do Grupo de Trabalho 2 ao Primeiro Relatório da Avaliação Nacional sobre Mudanças Climáticas. Impactos, vulnerabilidades e adaptação às mudanças climáticas. Rio de Janeiro, 2015.

PAINEL INTERGOVERNAMENTAL SOBRE AS MUDANÇAS CLIMÁTICAS (IPCC). Contribution of Working Group II to the Fifth Assessment Report. Climate Change 2014: Impacts, Adaptation, and Vulnerability. Part B: Regional Aspects. Suécia, 2014.

PAINEL INTERGOVERNAMENTAL SOBRE AS MUDANÇAS CLIMÁTICAS (IPCC). Working Group I Contribution To The IPCC Fifth Assessment Report. Climate Change 2013: the Physical Science Basis. Suécia: 2013.

RECONDO, F. A realidade do STJ em números. Disponível em: <https://jota.info/justica/os-numeros-stj-28012015>. Acesso em: 29 nov. 2017.

RIVERA, M. T. C. El cambio climático: análisis científico y jurídico del problema de la emisión de gases de efecto invernadero. Revista de Derecho Urbanístico y Medio Ambiente, v. XXXI, n. 156, 1997.

RIZZARDO, A. Curso de Direito Agrário. São Paulo: Revista dos Tribunais, 2014.

SANTOS, D. O Estado da Amazônia: uso da terra. Belém, PA: Instituto do Homem e Meio Ambiente da Amazônia (IAMAZON), 2013.

SARLET, I. W.; FENSTERSEIFER, T. Direito Ambiental: introdução, fundamentos e teoria geral. São Paulo: Saraiva, 2014.

STEINKE, E. T. Climatologia fácil. São Paulo: Oficina de Textos, 2012.

SUPERIOR TRIBUNAL DE JUSTIÇA (STJ). AgRg no AREsp: 476067 SP 2014/0032471-4, Relator: Ministro HUMBERTO MARTINS. Data de Julgamento: 22/05/2014. Órgão Julgador: T2 - SEGUNDA TURMA. Data de Publicação: DJe 28/05/2014. 
A atuação do poder judiciário brasileiro nos biomas amazônia e cerrado visando combater o aquecimento global

SUPERIOR TRIBUNAL DE JUSTIÇA (STJ). AgRg nos EDcl no REsp: 1094873 SP 2008/0215494-3. Relator: Ministro HUMBERTO MARTINS. Data de Julgamento: 04/08/2009. Órgão Julgador: T2 - SEGUNDA TURMA. Data de Publicação: DJe $17 / 08 / 2009$.

TRIBUNAL DE JUSTIÇA DO MATO GROSSO (TJMT). AI 81179/2006. Relator: SEBASTIAO BARBOSA FARIAS. Órgão Julgador: Quarta Câmara Cível. Julgado em 09/04/2007. Data de Publicação: DJe 23/04/2007.

TRIBUNAL DE JUSTIÇA DO PARÁ (TJPA). AC: 2009.02734377-77, 77.680. Relator: RICARDO FERREIRA NUNES. Órgão Julgador: 4ª Câmara Cível Isolada, Julgado em: 04/05/2009. Data de Publicação: DJe 15/05/2009.

TRIBUNAL DE JUSTIÇA DO RORAINA (TJRR). AC: 0030120001281, Relator: Des. JEFFERSON FERNANDES DA SILVA. Data de Publicação: DJe 05/11/2015.

TRIBUNAL DE JUSTIÇA DE SÃO PAULO (TJSP). APL: 00008956420028260042 SP 0000895-64.2002.8.26.0042. Relator: BONILHA FILHO. Data de Julgamento: 20/08/2014. Órgão Julgador: $11^{a}$ Câmara Extraordinária de Direito Privado. Data de Publicação: 21/08/2014.

TRIBUNAL DE JUSTIÇA DE SÃO PAULO (TJSP). APL: 00027274020088260619 SP 0002727-40.2008.8.26.0619. Relator: JOÃO NEGRINI FILHO. Data de Julgamento: 20/06/2013, Órgão Julgador: $1^{\text {a }}$ Câmara Reservada ao Meio Ambiente. Data de Publicação: 25/06/2013.

TRIBUNAL DE JUSTIÇA DE SÃO PAULO (TJSP). EI: 16474520088260165 SP 0001647-45.2008.8.26.0165. Relator: RENATO NALINI. Data de Julgamento: 03/02/2011. Órgão Julgador: Câmara Reservada ao Meio Ambiente. Data de Publicação: 10/02/2011.

TRIBUNAL DE JUSTIÇA DE SÃO PAULO (TJSP). REEX: 10050951020148260032 SP 1005095-10.2014.8.26.0032, Relator: DIMAS RUBENS FONSECA. Data de Julgamento: 15/10/2015 Órgão Julgador: $1^{a}$ Câmara Reservada ao Meio Ambiente. Data de Publicação: 23/10/2015.

VEYRET, Y. (Org.). Dicionário do Meio Ambiente. Tradução de Marcos Bagno. São Paulo: Senac São Paulo, 2012.

VIÑUALES, J. E. El régimen jurídico internacional relativo al cambio climático: perspectivas $\mathbf{y} \quad$ prospectivas. Disponível em: <http://www.oas.org/es/sla/ddi/docs/publicaciones_digital_xxxvi_curso_derecho_intern acional_2009_jorge_e_vinuales.pdf>. Acesso em: 5 nov. 2017.

VIOLA, E; FRANCHINI, M.; RIBEIRO, T. L. Sistema internacional de hegemonia conservadora: a governança global e democracia na era da crise climática. São Paulo: Annablume, 2013. 
Artigo recebido em 01 de dezembro de 2017 e aceito em 01 de outubro de 2018

${ }^{1}$ Tenha-se presente que $1 \mathrm{PgC}$ (um pentagrama de carbono) equivale a $10^{15} \mathrm{~g}$ ou a um bilhão de toneladas de carbono.

${ }^{2}$ O Pantanal é considerado uma das maiores extensões úmidas contínuas do planeta. Em uma área aproximada de $150.355 \mathrm{~km}^{2}$ - cerca de $1,75 \%$ da área total do território brasileiro -, abriga 263 espécies de peixes, 41 gêneros de anfíbios, 113 categorias de répteis, 463 tipos de aves diversas, bem como 132 modalidades de mamíferos. De acordo com o Programa de Monitoramento dos Biomas Brasileiros por Satélites, o bioma mantém 83,07\% de sua cobertura vegetal nativa (MMA, 2016).

${ }^{3}$ São eles: Acre, Amapá, Amazonas, Pará, Roraima e partes dos territórios do Maranhão, Mato Grosso, Rondônia e Tocantins.

${ }^{4}$ Dentro do regime climático internacional, cumpre observar que as florestas enquadram-se nas definições de reservoir, sink e source, desempenhando papel relevante no que tange à mitigação dos efeitos das alterações do clima, ou, ainda, caracterizando-se como fonte de GEE, a depender do uso que é empregado a elas.

${ }^{5}$ Dióxido de carbono equivalente $\left(\mathrm{CO}_{2} \mathrm{eq}\right)$ é uma unidade métrica que converte o potencial de aquecimento global de gases que provocam o efeito estufa - como o óxido nitroso e o metano em termos equivalentes às toneladas de $\mathrm{CO}_{2}$. (LAVRATTI; CAVEDON-CAPDEVILLE, 2015, p. 532).

${ }^{6}$ Entende-se por espécie endêmica aquela espécie animal ou vegetal que ocorre somente em uma determinada área ou região geográfica.

7 Salienta-se, entretanto, que as áreas de Cerrado integrantes da Amazônia Legal, como nos estados de Roraima, Tocantins e Mato Grosso, ainda que não estejam incluídas na categoria jurídica de patrimônio nacional, têm proteção equivalente.

${ }^{8} \mathrm{Na}$ busca de simetria jurídica em relação aos seis biomas brasileiros, cita-se também a PEC $\mathrm{n}$. 237, de 2008, que intenciona incluir o bioma Pampa como patrimônio nacional.

${ }^{9}$ Vale lembrar que o Cerrado é responsável pela produção de aproximadamente $60 \%$ de toda soja e cerca de $75 \%$ de todo o milho colhido anualmente no Brasil, além de gerar expressiva oferta de cana-de-açúcar, arroz, feijão e trigo, por exemplo. Ademais, concentra mais de $55 \%$ da produção de carne vermelha, com um rebanho bovino estimado em 195 milhões de cabeças (MMA, 2014, p. 13).

${ }^{10}$ Para coordenar a implementação da Convenção-Quadro, instituiu-se uma complexa estrutura de órgãos, destacando-se a Conferência das Partes (COP), responsável pelo exame periódico do 
A atuação do poder judiciário brasileiro nos biomas amazônia e cerrado visando combater o aquecimento global

desenvolvimento do acordo, bem como por propiciar a tomada das decisões necessárias para promover o seu efetivo funcionamento.

${ }^{11}$ O Protocolo de Quioto entrou em vigor apenas em 2005, com a ratificação da Rússia.

${ }^{12}$ A expectativa de um segundo período de cumprimento do Protocolo de Quioto (2013-2020) se deu com a assinatura da Emenda de Doha, acordada na COP-18, no Qatar, em 2012. Até novembro de 2017, a Emenda de Doha ao Protocolo de Quioto foi ratificada por 83 Estados, quando careceria de 144 países para que produzisse efeitos. O Brasil, até o momento, não ratificou esse documento. De todo modo, os países que não aderiram ao prolongamento oficial do Protocolo de Quioto podem desenvolver ações voluntárias de proteção climática.

${ }^{13}$ Embora o período de 2013 a 2020 do regime climático esteja, por ora, dependente de ações voluntárias, as ações para o período pós-2020 estão previstas no Acordo de Paris, novo acordo do clima assinado na COP-21, no final de 2015. Tratam-se das Contribuições Nacionalmente Determinadas (NDC, na sigla inglesa) dos países, um conjunto de autopropostas acerca de medidas de mitigação das emissões de GEE e de adaptação às mudanças climáticas. O Acordo de Paris entrou em vigência em novembro de 2016 e foi ratificado - até novembro de 2017 por 166 dos 197 países que o assinaram. O Brasil assinou, ratificou e - por meio do Decreto $\mathrm{n}$. 9.073/2017 - internalizou em seu ordenamento jurídico o Acordo de Paris. A NDC brasileira, a ser efetuada no âmbito na PNMC, propõe a redução de 37\% das emissões de GEE em 2025 (com base nos níveis de GEE de 2005). Sobressai, portanto, a equivalência entre a meta da NDC do Brasil - 37\% em 2025 - e a vigente na PNMC - entre 36,1 e 38,9\% até 2020.

${ }^{14}$ Cf. Decreto Legislativo n. 7.390/2010, artigo $5^{\circ}$, inciso I.

${ }^{15}$ Cf. Decreto Legislativo n. 7.390/2010, artigo $6^{\circ}, \S 1^{\circ}$, inciso III.

${ }^{16}$ Cf. Decreto Legislativo n. 7.390/2010, artigo $6^{\circ}, \S 1^{\circ}$, incisos IV a IX.

${ }^{17}$ Cf. Decreto Legislativo n. 7.390/2010, artigo 6 ${ }^{\circ}$, § $1^{\circ}$, inciso X.

${ }^{18}$ A primeira fase ocorreu entre 2004 e 2008; a segunda fase, entre 2009 e 2011; e a terceira fase, entre 2012 e 2015.

${ }^{19}$ Cf. Decreto Legislativo n. 7.390/2010, artigo $6^{\circ}, \S 1^{\circ}$, inciso I.

${ }^{20}$ O índice de 2016 é o último valor consolidado disponível.

${ }^{21}$ No ano de 2012, o governo federal excluiu 91,3 mil hectares de sete unidades de conservação, cinco delas localizadas na região amazônica.

${ }^{22}$ São eles: em 2002, $21.651 \mathrm{~km}^{2}$; em 2003, $25.396 \mathrm{~km}^{2}$; e em 2004, $27.772 \mathrm{~km}^{2}$. Os outros índices mais elevados de desmatamento ocorreram em $1988\left(21.050 \mathrm{~km}^{2}\right)$ e $1995\left(29.059 \mathrm{~km}^{2}\right)$.

${ }^{23}$ A lei n. 9.605/1998 dispõe sobre as sanções penais e administrativas derivadas de condutas e atividades lesivas ao ambiente, entre outras providências.

${ }^{24}$ A lei n. $12.651 / 2012$ dispõe sobre a proteção da vegetação nativa.

${ }^{25}$ Cf. Decreto Legislativo n. 7.390/2010, artigo $5^{\circ}$. 
${ }^{26}$ Cf. Decreto Legislativo n. 7.390/2010, artigo $5^{\circ}$, inciso I.

${ }^{27}$ Cf. Anexo do Decreto Legislativo n. 7.390/2010, item 1.4

${ }^{28}$ Dado obtido a partir das taxas de desmatamento consolidadas pelo PRODES.

${ }^{29}$ Cf. Anexo do Decreto Legislativo n. 7.390/2010.

${ }^{30}$ Além da Amazônia e do Cerrado, o setor de mudança de uso da terra também abrange, ainda que com representações mínimas, a Mata Atlântica, a Caatinga e o Pantanal. Cf. Anexo do Decreto Legislativo n. 7.390/2010.

${ }^{31}$ Acre, Amapá, Amazonas, Maranhão, Mato Grosso, Pará, Rondônia, Roraima e Tocantins.

${ }^{32}$ Decisão monocrática consiste em decisão proferida por um único magistrado, de qualquer instância ou tribunal.

33 Cita-se, como exemplo, decisão que assim dispõe: "É verdade que o Brasil nunca se interessou de maneira séria e consistente pelo seu maior patrimônio, a natureza. Submeteu-se, desde a colonização lusa, a um cruel sistema de exploração destrutiva. [...] O ritmo dendroclasta [de degradação] prossegue, conforme notícia a imprensa internacional, após constatar o que ocorre com a Floresta Amazônica, última grande mata nativa tropical do planeta. [...] A propósito, James Lovelock, o formulador da hipótese Gaia, alerta que o mundo está irremediavelmente comprometido pelo aquecimento global e que talvez não haja possibilidade de retorno. O que está em jogo não é apenas a qualidade de vida, senão a própria sobrevivência no Planeta (BRASIL. STJ, 2014)" (grifo nosso).

${ }^{34}$ Menciona-se, nesse sentido, julgado que relaciona a incidência de incêndios florestais a causas naturais: "Entre os dias 8 de fevereiro a 8 de abril de 2010, quando o IBAMA/Prevfogo (sede e local) atrelou-se a estrutura estadual de Defesa Civil na chamada Operação Roraima Verde, que fora montada para fazer frente aos incêndios florestais que se acentuaram em função das condições climáticas de seca intensificadas pelo fenômeno El Niño. Responsabilidade objetiva do Estado configurada, pois é de se concluir que a ocorrência do incêndio se deu em razão de causas naturais, por mudanças climáticas, também, ocorridas em anos anteriores e passíveis de previsão. Assim, os prejuízos poderiam, em tese, ser evitados ou minorados se o Corpo de Bombeiro Militar do Estado de Roraima tivesse agido, preventivamente e, no dia do incêndio (BRASIL, TJRR, 2015)" (grifo nosso).

35 Amapá, Amazonas, Bahia, Goiás, Maranhão, Mato Grosso, Mato Grosso do Sul, Minas Gerais, Paraná, Piauí, Rondônia, Roraima, São Paulo e Tocantins.

36 Antigo artigo 27 do Código Florestal revogado (Lei n. 4.771/1965), posteriormente regulamentado pelo Decreto n. 2.661/1998.

${ }^{37}$ A proibição de queima prevista no aludido artigo abrange todas as formas de vegetação, inclusive as culturas renováveis, tal qual a cana-de-açúcar decorrente da atividade agrícola.

${ }^{38}$ Cf. artigo $2^{\circ}$ da Lei Estadual n. 13.798/2009.

${ }^{39}$ Cf. artigo $5^{\circ}$ da Lei Estadual n. 13.798/2009.

${ }^{40}$ Cf. artigo $6^{\circ}$ da Lei Estadual n. 13.798/2009. 
A atuação do poder judiciário brasileiro nos biomas amazônia e cerrado visando combater o aquecimento global

${ }^{41}$ Cf. artigo $8^{\circ}$ da Lei Estadual n. 13.798/2009.

${ }^{42}$ Como exemplo, cita-se o Acórdão n. 0363759-16.2010.8.26.000 e o Acórdão n. 000200591.2011.8.26.0589, ambos de julho de 2014. 